\title{
Modulation of tropical ocean surface chlorophyll by the Madden-Julian Oscillation
}

\author{
Daeho Jin · Duane E. Waliser • Charles Jones • \\ Raghu Murtugudde
}

Received: 27 September 2011/Accepted: 16 February 2012/Published online: 11 March 2012

(C) The Author(s) 2012. This article is published with open access at Springerlink.com

\begin{abstract}
The MJO modulation of sea surface chlorophyll-a (Chl) examined initially by Waliser et al. in Geophys Res Lett, (2005) is revisited with a significantly longer time-series of observations and a more systematic approach to characterizing the possible mechanisms underlying the MJO-Chl relationships. The MJO composite analysis of $\mathrm{Chl}$ and lead-lag correlations between $\mathrm{Chl}$ and other physical variables reveal regional variability of $\mathrm{Chl}$ and corresponding indicative temporal relationships among variables. Along the path of the MJO convection, wind speed-a proxy for oceanic vertical turbulent mixing and corresponding entrainment-is most strongly correlated with $\mathrm{Chl}$ when wind leads $\mathrm{Chl}$ by a few days. Composite $\mathrm{Chl}$ also displays MJO influences away from the path of the MJO convection. The role of wind speed in those regions is generally the same for Chl variability as that along the path of the MJO convection, although Ekman pumping also plays a role in generating Chl variability in limited regions. However, the wind forcing away from the MJO convection path is less coherent, rendering the temporal link relatively weak. Lastly, the potential for bio-physical feedbacks at the MJO time-scale is examined. The correlation analysis provides tantalizing evidence for local bio-feedbacks to the
\end{abstract}

D. Jin $(\square) \cdot$ R. Murtugudde

Earth System Science Interdisciplinary Center,

University of Maryland, College Park, MD, USA

e-mail: daehojin@umd.edu

D. E. Waliser

Jet Propulsion Laboratory, California Institute of Technology,

Pasadena, CA, USA

C. Jones

Earth Research Institute, University of California, Santa Barbara,

CA, USA physical MJO system. Plausible hypothesis for Chl to amplify the MJO phase transition is presented though it cannot be affirmed in this study and will be examined and reported in a future modeling study.

\section{Introduction}

Chlorophyll-a (Chl) concentration is an indicator of photosynthetic activity in the ocean. Chl absorbs light in select spectral bands and hence, in clear-sky regions, is detectable from space. Light absorbed by $\mathrm{Chl}$ is converted to heat, and thus the upper ocean vertical structure is affected (e.g., Lewis et al. 1983, 1990; Siegel et al. 1995). It has also been shown that Chl can have significant impact on large-scale ocean dynamics, coupled climate variability, and even on (atmospheric) cyclone activity (e.g., Gnanadesikan et al. 2010; Jochum et al. 2010; Lengaigne et al. 2007; Manizza et al. 2008; Marzeion et al. 2005; Murtugudde et al. 2002; Sweeney et al. 2005; Wetzel et al. 2006) although the mechanisms and the associated details continue to be debated. This raises the interesting possibility of biophysical feedbacks from Chl to tropical intraseasonal variability. This was considered by Gildor et al. (2003), who suggest that the existence of plankton can result in a perturbation of sea surface temperature (SST) which in turn may be amplified in the atmosphere through radiativeconvective oscillation.

The Madden-Julian Oscillation (MJO) is the dominant mode of atmospheric intraseasonal variability that serves as a bridge between weather and climate. The MJO is characterized by eastward-moving tropical deep convection system originally observed as 40-50 day oscillations (Madden and Julian 1971, 1994) with clearly identifiable fluctuations in surface wind, precipitation, shortwave 
radiation, etc. (see Lau and Waliser 2005 and Zhang 2005 for recent reviews). Generally it is known that the MJO convection activity is strong in the Indo-Pacific warm pool region, and vanishes as the SST in the eastern tropical Pacific becomes cooler although dynamic signatures in the upper troposphere continue to propagate eastward.

Oceanic responses to the MJO are usually categorized into two main processes, viz., a localized mixed layer response and a wave response. The mixed layer response has traditionally been examined in the Indo-Pacific warm pool region. The SST is affected by the MJO associated fluctuations in solar radiation and latent and sensible heat fluxes (see Hendon 2005 for recent review). SST changes and additional fresh water flux perturbations, due to precipitation and evaporation, result in buoyancy and salinity flux changes (e.g., Parampil et al. 2010; Zhang and McPhaden 2000). The temporal phase relationship among heat flux, wind (stress), and SST perturbations before and after the MJO convection are discussed and summarized in several observational studies (e.g., Hendon and Glick 1997; Lau and Sui 1997; Woolnough et al. 2000; Zhang and Anderson 2003; Zhang and McPhaden 2000).

The MJO convection system also affects the ocean through wind-induced equatorial Kelvin wave activity in the equatorial Pacific (e.g., Enfield 1987; Hendon et al. 1998; Kessler et al. 1995; McPhaden 2002). Eastward propagating Kelvin waves are initiated in the western tropical Pacific, and the phase speed of those become slower from the central to eastern tropical Pacific (Roundy and Kiladis 2006). In the eastern tropical Pacific, vertical entrainment (McPhaden 2002) and meridional advection (Lucas et al. 2010) have both been shown to be important processes for impacting eastern Pacific intraseasonal SST variability (also see Halkides et al. 2011).

Ocean dynamical responses to the MJO in the Indian Ocean are also reported in several studies (e.g., Fu 2007; Han et al. 2001; Sengupta et al. 2001a, b; Webber et al. 2010; Zhou and Murtugudde 2010). For example, Fu (2007) identified dominant modes of intraseasonal variability in the Indian Ocean, using sea surface height (SSH), temperature, and wind data. Zhou and Murtugudde (2010) also used observational data around the eastern Indian Ocean and the Maritime Continent, and argued that the oceanic intraseasonal variability is directly affected by the corresponding atmospheric forcing. In addition, Webber et al. (2010) identified equatorial Kelvin waves and reflected Rossby waves in the tropical Indian Ocean based on MJO phase composites. The authors suggested an interesting hypothesis from these wave responses that the ocean can provide a feedback to the subsequent MJO. They showed that the arrival of the reflected Rossby wave in the western Indian Ocean leads to a local warmer SST anomalies, and these anomalies have the potential for initiating a new MJO event.

Beyond the dynamical ocean responses, ocean ecosystem responses to the MJO have also begun to be investigated (e.g., Isoguchi and Kawamura 2006; Resplandy et al. 2009; Waliser et al. 2005; hereafter WET05). Mechanistically, ocean dynamics and thermodynamics affect $\mathrm{Chl}$ concentrations via nutrient supply, light penetration, and environmental conditions such as temperature variability. Kahru et al. (2010) argued based on monthly data that the main limiting factor controlling $\mathrm{Chl}$ growth in most tropical and subtropical oceans (except the equatorial eastern Pacific) is generally the nutrient availability rather than light. Related to the nutrient supply, common oceanic processes inducing Chl blooms are described in McCreary et al. (2009). The processes include (1) upwelling, (2) entrainment, (3) detrainment, (4) subsurface (deep) phytoplankton maxima (DCMs), and (5) advection. Among them, upwelling and entrainment are most notable because both processes actively supply nutrients from the deeper ocean to the near-surface. In the open ocean, upwelling occurs by a curl of wind stress or equatorial divergence, and entrainment occurs by increasing surface wind and corresponding turbulent mixing. Hence, we expect winds to play significant role for intraseasonal Chl variability as suggested in WET05.

Using 5 years of Sea-viewing Wide Field-of-view Sensor (SeaWiFs) data, WET05 averaged satellite-derived ocean color data into pentads around the peak of the MJO in the tropical Indo-Pacific Ocean and identified a number of regions where the $\mathrm{Chl}$ anomalies were significant. They further examined the cursory relationships among Chl, wind speed, and surface shortwave flux in those regions. The main finding of their study was that the variability in the entrainment of nutrient-rich waters into the mixed layer could be induced by MJO-related wind variation, and this was likely driving a large part of the spatio-temporal modulation of $\mathrm{Chl}$ at intraseasonal time-scales.

The first objective of this manuscript is to extend and complement WET05. Since their study, two developments have occurred that justify revisiting this issue. The first is that ocean color satellite data, specifically SeaWiFS data has accrued for over 13 years making it tempting to seek more robust and statistically significant results (the 5 years of data used by WET05 is marginally adequate for MJO sampling, particularly when requiring clear-sky footprints for the $\mathrm{Chl}$ retrievals). We also expect improved quality of SeaWiFS data by the revised reprocessing algorithms (http://oceancolor.gsfc.nasa.gov/WIKI/OCReproc.html). The second is the establishment of a community standard for the MJO identification and life-cycle compositing, i.e., the "Real-time Multivariate MJO series (RMM)" index (Wheeler and Hendon 2004; details are in Sect. 2) which 
enables a better depiction of MJO composites based on daily data (e.g., Waliser et al. 2009).

The second objective is to provide a more robust analysis of the possible physical mechanisms for the MJO-Chl relationships, and their potential for bio-physical feedbacks between the upper ocean biological responses at the MJO time-scale and the MJO itself. To first order, it is known that a perturbation of $\mathrm{Chl}$ concentration in the upper ocean affects the penetration profile of solar radiation. Most studies cited above have argued that this affects not only the local SST, but also interacts with the large-scale ocean circulation and thus possibly results in coupled climate feedbacks. We simply consider an extension of these arguments to hypothesize that the interaction between the MJO and the oceanic ecosystem has the potential for reorganizing intraseasonal SSTs and hence feedback on the evolution of MJOs.

This manuscript is organized as follows. Data and the analysis method are described in Sect. 2. In Sect. 3, MJO composites are presented. The effects of the MJO on the sea surface $\mathrm{Chl}$ are examined with the temporal evolutions over longitude of the meridional mean in the selected regions: along the path of the MJO convection in boreal winter and summer, and an example away from the path of the MJO convection, i.e., northern tropical region. A summary with conclusions is presented in Sect. 4.

\section{Data and method}

\subsection{Observational data}

Observational variables analyzed in this study are the outgoing longwave radiation (OLR) at the top of atmosphere, SST, surface wind and wind stress, mean sea level anomaly (MSLA), and surface Chl concentration. The daily mean OLR data $\left(2.5^{\circ} \times 2.5^{\circ}\right)$ is obtained from the Advanced Very High Resolution Radiometer (AVHRR) of the National Oceanic and Atmospheric Administration (NOAA) satellites (Liebmann and Smith 1996). ${ }^{1}$ The daily SST is version 2 of the NOAA optimal interpolation $\left(0.25^{\circ} \times 0.25^{\circ}\right)$, which combines satellite data with in situ observations. This product uses basically the AVHRR infrared satellite SST data and is blended with the Advanced Microwave Scanning Radiometer (AMSR) data when available (Reynolds et al. 2007). The wind data comes from the cross-calibrated, multi-platform (CCMP), multi-instrument ocean surface wind velocity data set (Atlas et al. 1996). Level $3.0,0.25^{\circ} \times 0.25^{\circ}$ data is used,

\footnotetext{
${ }^{1}$ Interpolated OLR data provided by the NOAA/OAR/ESRL PSD, Boulder, Colorado, USA, from their Web site at http://www.esrl. noaa.gov/psd/.
}

and 6-hourly time scale is converted to daily data. All three data products are aggregated to $1^{\circ} \times 1^{\circ}$ bins for convenience, and anomaly from the climatological seasonal cycle is band-pass filtered (30-120 days) with a 251-points Lanczos filter (Duchon 1979). In addition, for sea surface height data, we used MSLA data provided by Archiving, Validation and Interpretation of Satellite Oceanographic data (Aviso). ${ }^{2}$ We used the "delayed time," "reference," and "merged" data for temporal consistency. The data is available weekly and $1^{\circ} \times 1^{\circ}$ resolution, thus the weekly anomaly from climatology is interpolated to daily data, and the same Lanczos band-pass filter is applied.

The wind stress is estimated from CCMP daily wind data as

$\vec{\tau}=\rho C_{D}\|\vec{V}\| \cdot \vec{V}$

where $\rho$ is the density of surface air, $C_{D}$ is the drag coefficient, and vector $V$ is the zonal and meridional surface wind. The drag coefficient, $C_{D}$ is known to depend on the wind speed (e.g., Wu 1982), but the effective drag coefficient in tropical region is relatively constant (Trenberth et al. 1989). Hence, for convenience, we used a constant $C_{D}=1.2 \times 10^{-3}$, and $\rho=1.17 \mathrm{~kg} / \mathrm{m}^{3}$. The meridional mean of the zonal wind stress ("Tau_x" hereafter) in the equatorial band $\left(3^{\circ}-7^{\circ} \mathrm{S}\right.$ in this study), and wind stress curl ("Tau_Curl" hereafter) away from the equatorial region is calculated as a measure of Ekman divergence and thus upwelling. The meridional mean of Tau_x in the narrow equatorial band is justified by the fact that the zonal wind response to the $\mathrm{MJO}$ in the composite analysis is meridionally uniform from approximately $10^{\circ} \mathrm{S}-10^{\circ} \mathrm{N}$ (not shown). The filtering process of wind stress data is same as the CCMP wind speed data.

The Chl data is the level-3 standard mapped image (SMI) product of SeaWiFS (McClain et al. 2004). The Chl data is first $\log 10$-transformed before any of the calculations described below. The reason for this transform is because the Chl data can be approximated as a lognormal distribution (Campbell 1995). The original $9 \mathrm{~km}$ resolution data is aggregated up to $1^{\circ} \times 1^{\circ}$, and horizontally smoothed. Like other variables, a daily version of Chl data is available, but it includes considerable amounts of missing data due to clouds, which prohibits application of the same Lanczos band-pass filter discussed above. Hence, we prepared two Chl data sets, viz., an 8-day composite and a 32-day rolling mean data. The 8-day composite data has much less missing data than the daily composite data, and the 32-day rolling mean data has even less missing data than the 8-day composite data. For the first step, the 32-day

\footnotetext{
$\overline{2}$ The altimeter products were produced by Ssalto/Duacs and distributed by Aviso, with support from Cnes (http://www.aviso.oceanobs. com/duacs/).
} 
rolling mean data is interpolated to daily data, and Lanczos low-pass (120-day) filter is applied. Thus this filtered data represents the seasonal cycle and (interannual) low frequency characteristics of Chl. Second, this low frequency data is subtracted from the 8-day composite data. Then, the remainder is expected to represent high frequency anomalies, shorter than 120-days. Third, a 1-2-1 filter is applied to this 8-day anomaly data in order to remove higher frequency signals, with periods shorter than 16 days. Lastly, the 8-day band-pass filtered anomaly data is linearly interpolated to the daily time-scale. Our intention for this sequence of calculations is to provide a reasonable substitute for the 30-120 day Lanczos band-pass filter used for other variables.

One result of the series of calculations above is that the long term mean of $\mathrm{Chl}$ anomalies is not zero. For example, in the northern subtropical Pacific, boreal summer or winter period average of $\mathrm{Chl}$ anomalies (in the form of Log10Chl) is biased to the negative, approximately -0.05 . This difference is roughly similar in size to one standard deviation of Chl anomalies for whole summer or winter period (not shown). This bias originates from artifacts from the filtering processes as well as the inaccuracy of the 8-day composite and the 32-day running mean data due to significant missing data points in daily data. In order to exclude these systematic errors, each MJO phase composite is compared to the No-MJO composite instead of examining the MJO phase composite itself. Details about MJO and No-MJO composites, and an application to the Student's $t$ test are explained in the next Subsects. 2.2 and 2.3.

Reiterating the processing applied to the Chl data: (1) values are $\log 10$ transformed, (2) the data are then filtered to retain intraseasonal variations, and (3) composites for the MJO phases 1-8 and No-MJO case are constructed. All analyses in this study are performed with these log-transformed, filtered, and composited Chl anomalies. In addition, the period of Chl data used in this study is from November 1997 to October 2010, which covers 13 summer and winter seasons, respectively, providing a significantly greater sample size over the 5 years used in WET05. The period of all other datasets is also the same as that of Chl data except the CCMP wind data, which is only up to 2009 , beyond which the data was not available.

\subsection{Identification of the MJO}

The Real-time Multivariate MJO (RMM) series is used to identify the presence and the phase of the MJO. The RMM indices are principal components derived from combined EOF analysis of tropical OLR and zonal winds (Wheeler and Hendon 2004). The MJO phase is defined from the two-dimensional phase space constructed with RMM1 and RMM2, and the MJO strength is expressed as the squared- sum of RMM1 and RMM2. Daily RMM indices, and MJO phase and strength information are available online at http://www.bom.gov.au/climate/mjo/. In this study, MJO events are selected when the MJO strength exceeds 1 . In addition, the days when the MJO strength is less than 1 are defined as No-MJO events, which is a control group compared to the MJO events. One reason for specifying the control is because we can perform more robust statistical tests. This is because samples in any phase of MJO composite are completely excluded from those in the control.

This criterion for the MJO composite, larger in strength than 1 , is simple and a community standard. However, this is not a perfect method because the evolution of the MJO from initiation to decay is not necessarily maintained at strength larger than 1. Sometimes, over the MJO life cycle, the MJO strength decreases to slightly below 1 though the MJO convection still propagates (Jones and Carvalho 2009), and those MJO days would be relegated to the NoMJO composite in this study. Nevertheless, it is assumed that the effect of classification is minor in terms of composite mean. The same concept as No-Event composite but for an ENSO study has already been applied in Jin and Kirtman (2009). Lastly, it is also known that the MJO displays a strong seasonality. Hence, MJO events are segregated into the boreal summer (May-October) and boreal winter (November-April) events (e.g., Waliser 2006). The number of days for each MJO phase and No-MJO category in each season is summarized in Table 1.

\subsection{Analysis method}

The significance of the MJO composite anomaly is tested by the Student's $t$ test. The Log10Chl anomaly composite for each MJO phase is dominated by the systematic errors previously noted, so the composite patterns look similar among the MJO phases. These systematic errors could be excluded by performing the $t$ test for the anomaly differences, e.g. [the MJO phase $n$ composite-the control (i.e., No-MJO composite)]. These anomaly differences actually indicate a ratio, [the $\mathrm{MJO}$ composite/the control] because of the nature of the logarithm. Based on a preliminary $F$ test, if the variance ratio is less than $10 \%$ or larger than $90 \%$ at a specific grid point, a $t$ test formula for the case of unequal variance is used instead of pooled variance. Degrees of freedom are estimated by the equivalent sample size which is derived from the lag-1 autocorrelation of unfiltered anomaly data:

$n^{\prime}=\frac{1-\alpha_{1}}{1+\alpha_{1}} n$

where $n$ is the original sample size, $n^{\prime}$ is the equivalent sample size, and $\alpha^{1}$ is the lag-1 autocorrelation coefficient. This simple formula is derived by assuming that the 
Table 1 Number of days for MJO composite analysis from November 1st, 1997 to October 31st, 2010

\begin{tabular}{lllllllllll}
\hline MJO phase & 1 & 2 & 3 & 4 & 5 & 6 & 7 & 8 & MJO all & No-MJO \\
\hline Nov-Apr & 127 & 191 & 227 & 177 & 204 & 213 & 179 & 161 & 1,479 & 907 \\
May-Oct & 279 & 249 & 113 & 171 & 195 & 154 & 138 & 210 & 1,509 & 883 \\
\hline
\end{tabular}

unfiltered anomaly time series is the first order autoregressive process $(\mathrm{AR}(1))$. In the case of $\mathrm{Chl}$, the anomalies of the 8-day composite (before applying 1-2-1 filter or linear interpolation to daily data) behave like $\operatorname{AR}(1)$, so the equivalent sample size is calculated from this 8-day anomaly data. The equivalent sample size of $\mathrm{Chl}$, which is generally the least among observational datasets in this study, is mostly in the range of 30-60 except in persistently cloudy regions. For example, in the Northern Indian Ocean in boreal summer, the equivalent sample size is below 10 because of the persistent clouds in the monsoon season. Due to these widely varying degrees of freedom grid point by grid point, the same $t$ value at the separated grid points doesn't mean the same significance level (\%). Hence, for convenience, the results of the $t$ test are shown as the significance level itself (\%; black contour line in Figs. 1, 2) instead of statistical $t$ value.

Lastly, the local temporal relationships between the Log10Chl and other variables in the context of MJO evolution are examined with lead-lag correlation analysis. We first build a discrete time series of other variables including only the days of MJO strength exceeding 1 , and the corresponding lead/lag time-series of Log10Chl. The correlation coefficients are then calculated with these time-series at each grid point.

\section{Results}

\subsection{Horizontal view of MJO modulation}

The composite of all eight MJO phases in the boreal winter and summer seasons are presented in Figs. 1 and 2, respectively. To interpret the anomaly difference of the Log10Chl, it should be pointed out that a magnitude of 0.04 indicates that the ratio of the MJO composite over the No-MJO composite is $10^{0.04}$ which is approximately a $9.6 \%$ increase compared to the control. Similarly, -0.04 means an $8.8 \%$ decrease in MJO composite compared to the control. Student's $t$ test results at the $95 \%$ significance level for each MJO composite against the No-MJO composite are contoured (black line). Based on this, Figs. 1 and 2 indicate that most $\mathrm{Chl}$ signals related to the MJO are statistically significant.

In the boreal winter season (November to April), the MJO convection propagates eastward along the equator.
Figure 1 shows that $\mathrm{Chl}$ signals also propagate eastward. For example, from MJO phase 1 to 4 in the northern tropical Pacific, positive anomalies of Log10Chl travel from east of the Philippines to the central northern tropical Pacific. Subsequently, negative anomalies follow positive signals from phase 5 to 8 .

The atmospheric signatures of the MJO propagation in boreal summer (May-October) are different from those in boreal winter. For example, the MJO convection moves northward in the eastern Indian ocean (e.g., Waliser 2006). The corresponding Chl signals are also seen along a similar trajectory. For instance, from MJO phase 1 to 4 (Fig. 2ad), negative signals progress from the southern Bay of Bengal to the South China Sea. Similar movement of positive signals is also evident from phase 4 to 7 (Fig. 2d-h).

Besides the propagating feature, there are a few common and contrasting features between Figs. 1 and 2. First, it is notable that the boreal winter Chl signals are relatively organized compared to the boreal summer signals, especially in the Pacific sector. Secondly, in boreal summer, Chl signals are sometimes of the same sign all along the longitudes from the Indian Ocean to the central Pacific. For example, in Fig. 2e, f, positive anomalies exist along the tropics from $60^{\circ} \mathrm{E}$ to $150^{\circ} \mathrm{W}$. This kind of pattern does not appear in boreal winter. Thirdly, asymmetric signals are commonly detected in both figures. Here, symmetry means that similar shape with opposite sign of composite anomalies appears between MJO phase $n$ and $n+4$. Contrarily, asymmetry means that a signal of one sign is detected at phase $n$, but the other sign at phase $n+4$ is weak or not detected. One example is around $165^{\circ} \mathrm{E}$ and $20^{\circ} \mathrm{N}$ in panels a and e of Fig. 1. Here, strong negative signals are shown at MJO phase 5, but nearly no positive signals occur at MJO phase 1.

Previously WET05 also presented the MJO composite pattern of $\mathrm{Chl}$ in their Fig. 2. It is hard to directly compare the composite results between the two studies because of the different methods for identifying MJO events and phases and for calculating $\mathrm{Chl}$ perturbations. If we roughly compare the general characteristics, in the boreal winter season, the 0-day lag in their figure corresponds to MJO phases 2 or 3 here. At these phases, the suppressed Chl concentrations around the Maritime Continent are similar to each other. The bloom of $\mathrm{Chl}$ in the northern tropical Pacific at 10-day lag in their study is of similar shape and 


\section{10 NovApr MJO Anomaly Deviation Composite SeaWiFS Log10Chl}

(a) MJO Phase 1 - No-MJO

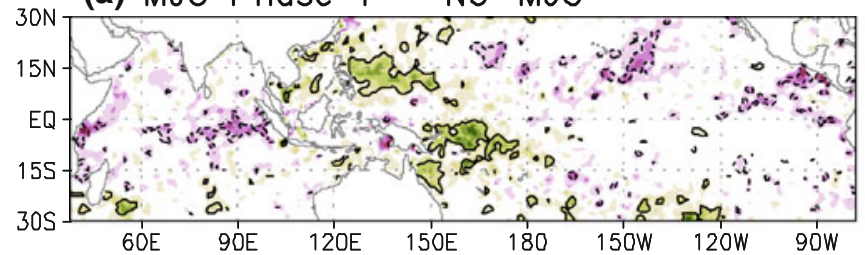

(b) MJO Phase 2 - No-MJO

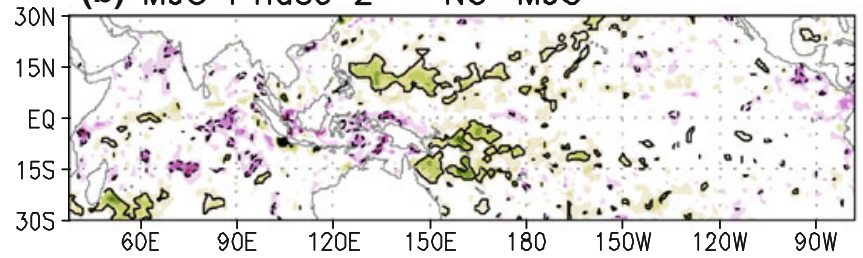

(c) MJO Phase 3 - No-MJO

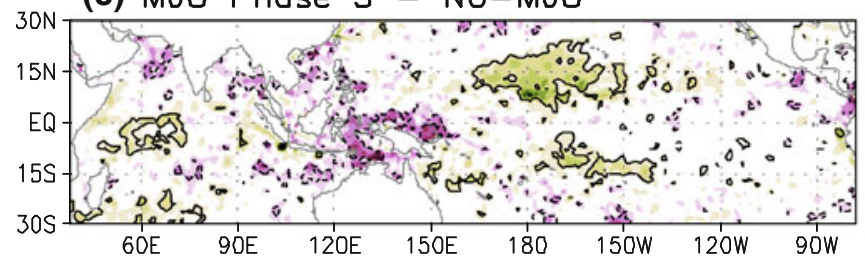

(d) MJO Phase 4 - No-MJO

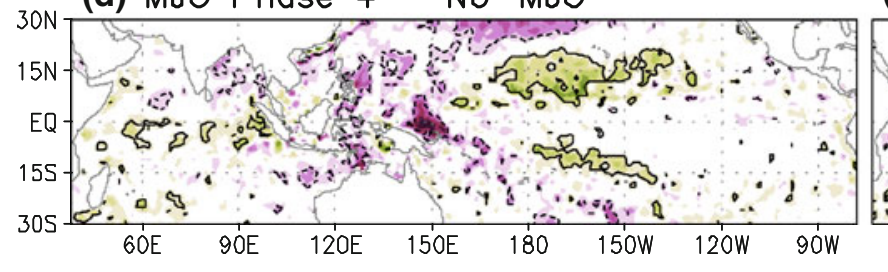

(e) MJO Phase 5 - No-MJO

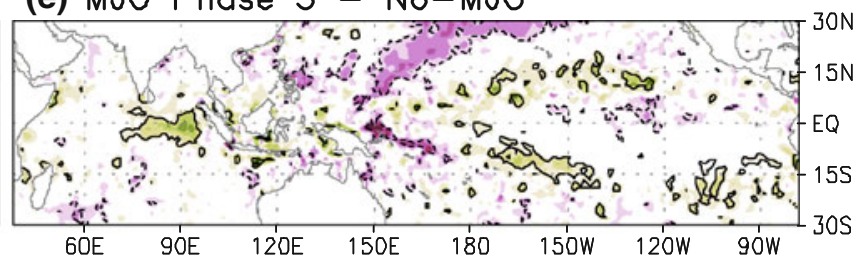

(f) MJO Phase 6 - No-MJO

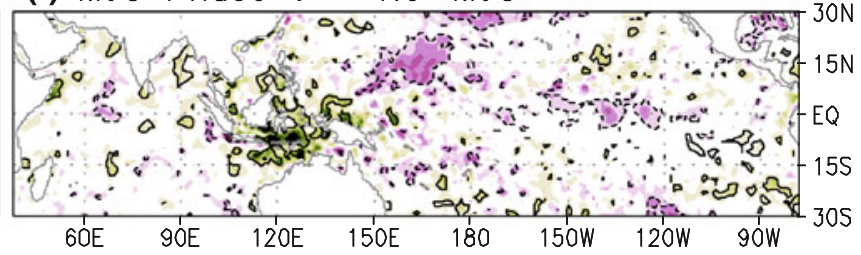

(g) MJO Phase 7 - No-MJO

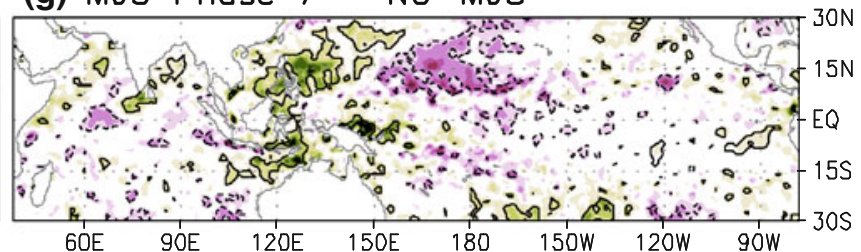

(h) MJO Phase 8 - No-MJO

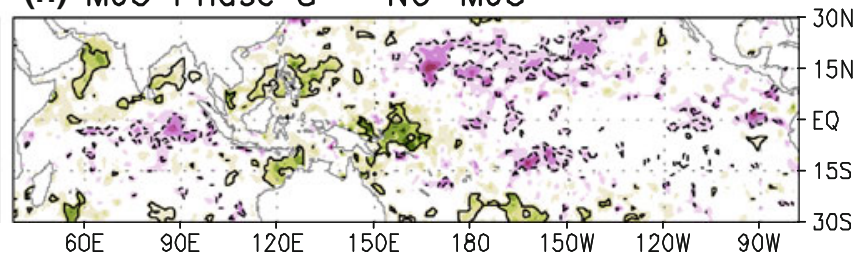

$\begin{array}{llllllllllll}-0.06 & -0.05 & -0.04 & -0.03 & -0.02 & -0.01 & 0.01 & 0.02 & 0.03 & 0.04 & 0.05 & 0.06\end{array}$

$-12.9 \%-10.9 \%-8.8 \%-6.7 \%-4.5 \%-2.3 \% \quad 2.3 \% \quad 4.7 \% \quad 7.2 \% \quad 9.6 \% \quad 12.2 \% 14.8 \%$

Fig. 1 Boreal winter (November-April) MJO anomaly deviation composite of SeaWiFS chlorophyll (Log10Chl) are shown (color shading). Here the deviation is from the anomaly composite and the No-MJO composite mean after the $\log 10$ transformation. Black

location at MJO phases 3 or 4 (Fig. 1c, d). However, the prominent variations in the Arabian Sea in their study do not appear in Fig. 1.

In boreal summer, the 0-day lag in WET05 corresponds to MJO phase 6 in Fig. 2. At this time, the longitudinally extended band of increased $\mathrm{Chl}$ concentration from the Bay of Bengal to the eastern tropical North Pacific is common to both studies. In addition, their study shows the negative to positive transition of $\mathrm{Chl}$ anomaly in the Bay of Bengal and the South China Sea from -20 to 20 lag days. A similar feature is also displayed in Fig. 2 from MJO phase 3-8. Differences between the two studies also exist in boreal summer. In WET05 there is a band of negative Chl anomalies in the northern tropical Pacific, from $165^{\circ} \mathrm{E}, 0^{\circ}$ to $135^{\circ} \mathrm{W}, 10^{\circ} \mathrm{N}$ at the 20 -lag day. This feature is not detected in Fig. 2. Actually in this region, there are lots of missing data due to the presence of clouds associated with contour line is $95 \%$ significance level of $t$ test, MJO composite against No-MJO composite. Anomaly deviation value of 0.01 in the $\log 10$ form means that the MJO phase composite concentration increases $2.3 \%$ over the No-MJO composite

the Intertropical Convergence Zone (ITCZ), particularly in MJO phases $4-8$ in this study. The prominent positive anomaly of $\mathrm{Chl}$ in the Arabian Sea in their study is another discrepancy between two studies. In this study, the $\mathrm{Chl}$ variability in the Arabian Sea is quite small compared to WET05. These discrepancies might be because of (1) sampling issue due to different period (5 vs. 13 years), (2) the difference in methods for calculating the MJO anomaly composite of $\mathrm{Chl}$, and/or (3) the improved reprocessing algorithm of ocean color data.

\subsection{View along the path of boreal winter MJO convection}

The propagating feature of the MJO can be shown best in a Hovmöller diagram. In order to see the MJO modulation, we chose the typical route of convection via a meridional 


\section{10 MayOct MJO Anomaly Deviation Composite SeaWiFS Log10Chl}

(a) MJO Phase $1-\mathrm{No}-\mathrm{MJO}$

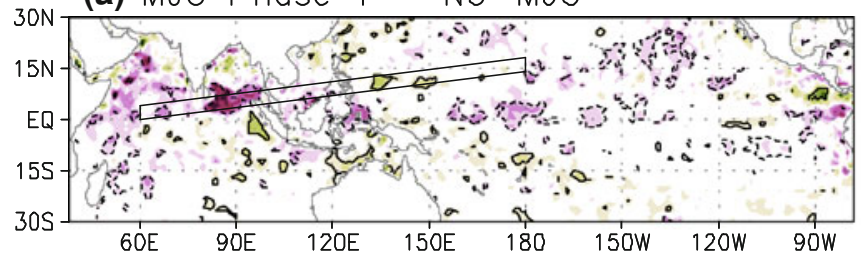

(b) MJO Phase 2 - No-MJO

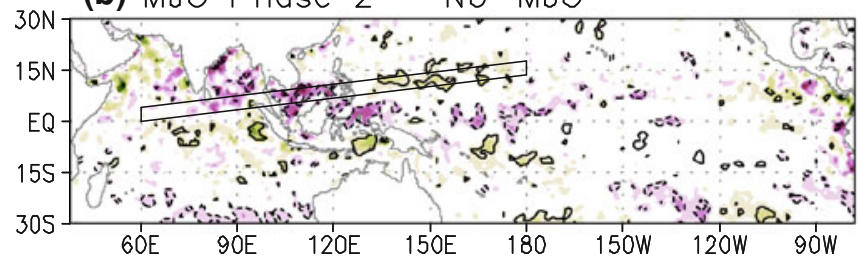

(c) MJO Phase 3 - No-MJO

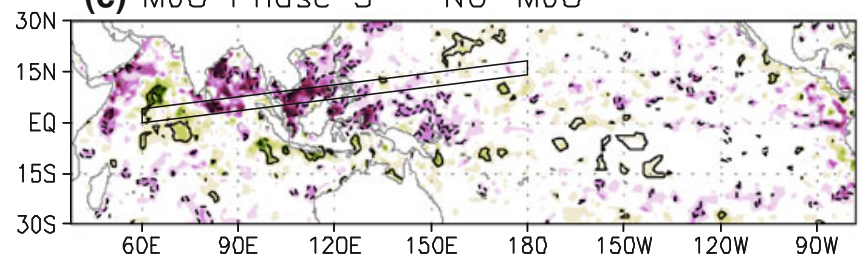

(d) MJO Phase 4 - No-MJO

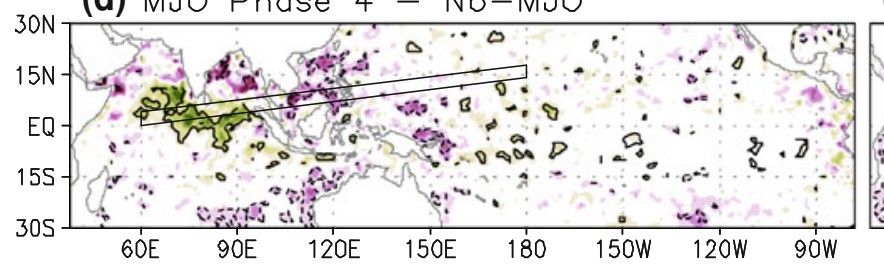

(e) MJO Phase 5 - No-MJO

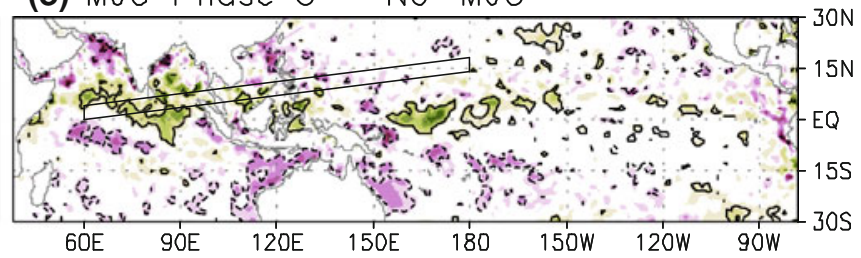

(f) MJO Phase 6 - No-MJO

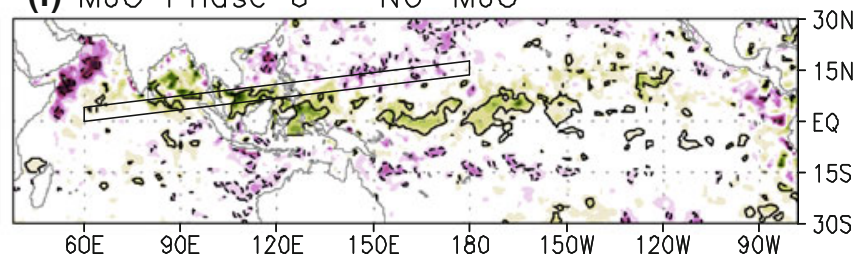

(g) MJO Phase 7 - No-MJO

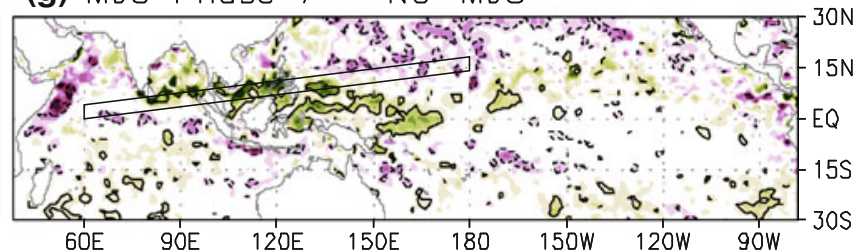

(h) MJO Phase 8 - No-MJO

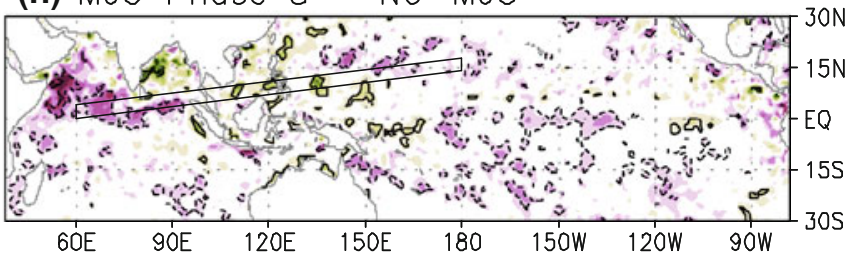

$\begin{array}{llllllllllll}-0.06 & -0.05 & -0.04 & -0.03 & -0.02 & -0.01 & 0.01 & 0.02 & 0.03 & 0.04 & 0.05 & 0.06\end{array}$

$-12.9 \%-10.9 \%-8.8 \%-6.7 \% \quad-4.5 \%-2.3 \% \quad 2.3 \% \quad 4.7 \% \quad 7.2 \% \quad 9.6 \% \quad 12.2 \% \quad 14.8 \%$

Fig. 2 Same to Fig. 1 but for the boreal summer season (May-October). Diagonal box indicates the region where meridional mean is calculated

mean over $3^{\circ}-7^{\circ} \mathrm{S}$ during boreal winter. Here, Hovmöller diagrams of MJO composites are presented with the time axis represented in terms of the MJO phase (i.e., 1-8). The same composite cycle is repeated two times to elucidate the oscillating feature of the MJO. In addition, the MJO convection is represented by red and blue lines at the same location in all panels, which are approximately fitted with lines to mark the peak phase of positive and negative OLR anomalies, respectively. Lastly, we should note that all variables are normalized as [(Phase $n$ anomaly composite-No-MJO anomaly composite)/standard deviation of No-MJO anomaly composite] for the purposes of convenient illustration. The standard deviation of No-MJO anomaly composite is assumed to represent the local internal variability and is independent of each MJO phase composite. This independence enables us to compare the relative strength of MJO composite anomalies after the normalization. The values of No-MJO anomaly composite standard deviation are presented in the "Appendix".
Figure 3 displays the typical MJO propagation during boreal winter. Tropical convection, represented by negative OLR, is clearly detected at $65^{\circ} \mathrm{E}$ during phase 2 , and moves eastward, closer to the Dateline by phase 7 (Fig. 3a). Chl growth and reduction occur between blue and red lines in the temporal sense, and eastward propagation of Log10Chl anomalies seems to stop around the Dateline though the MJO convection continues past the Dateline. Wind speed and SST (shadings in Fig. 3b, c) also show a transition of anomaly at similar longitudes where $\mathrm{Chl}$ propagation stops. Tau_x anomalies are closely related with the wind speed signals, but the same sign continues eastward over the Dateline. This means that the background climatological winds are mostly zonal, and of opposite directions to the east and west of $180^{\circ} \mathrm{E}$. This implies a surface convergence and corresponding convection of the Walker Circulation around $180^{\circ} \mathrm{E}$. In addition, it is worth noting that the wind speed and Tau_x anomalies do not propagate but seem to occur as a standing oscillation in the eastern tropical Pacific 
Fig. 3 Boreal winter meridional mean $\left(3^{\circ}-7^{\circ} \mathrm{S}\right) \mathrm{MJO}$ composite evolution of a Log10Chl (shaded) and OLR (contour), b wind speed (shaded) and zonal wind stress (contour), and c SST (shaded) and MSLA (contour) is shown. All contour intervals are same to the bottom (red and blue) shading levels, and solid (dash) line indicates positive (negative) values. All variables are normalized, and the same MJO composite is repeated for two cycles for convenience. Red and blue diagonal lines indicate peak signals of positive and negative OLR, respectively, so these are guides for the MJO propagation. The relative location of each propagation line in all panels is same. Left and center gray dash line indicates west and east boundary of the Maritime Continent, and the right gray line is on the Dateline where Chl propagation stops
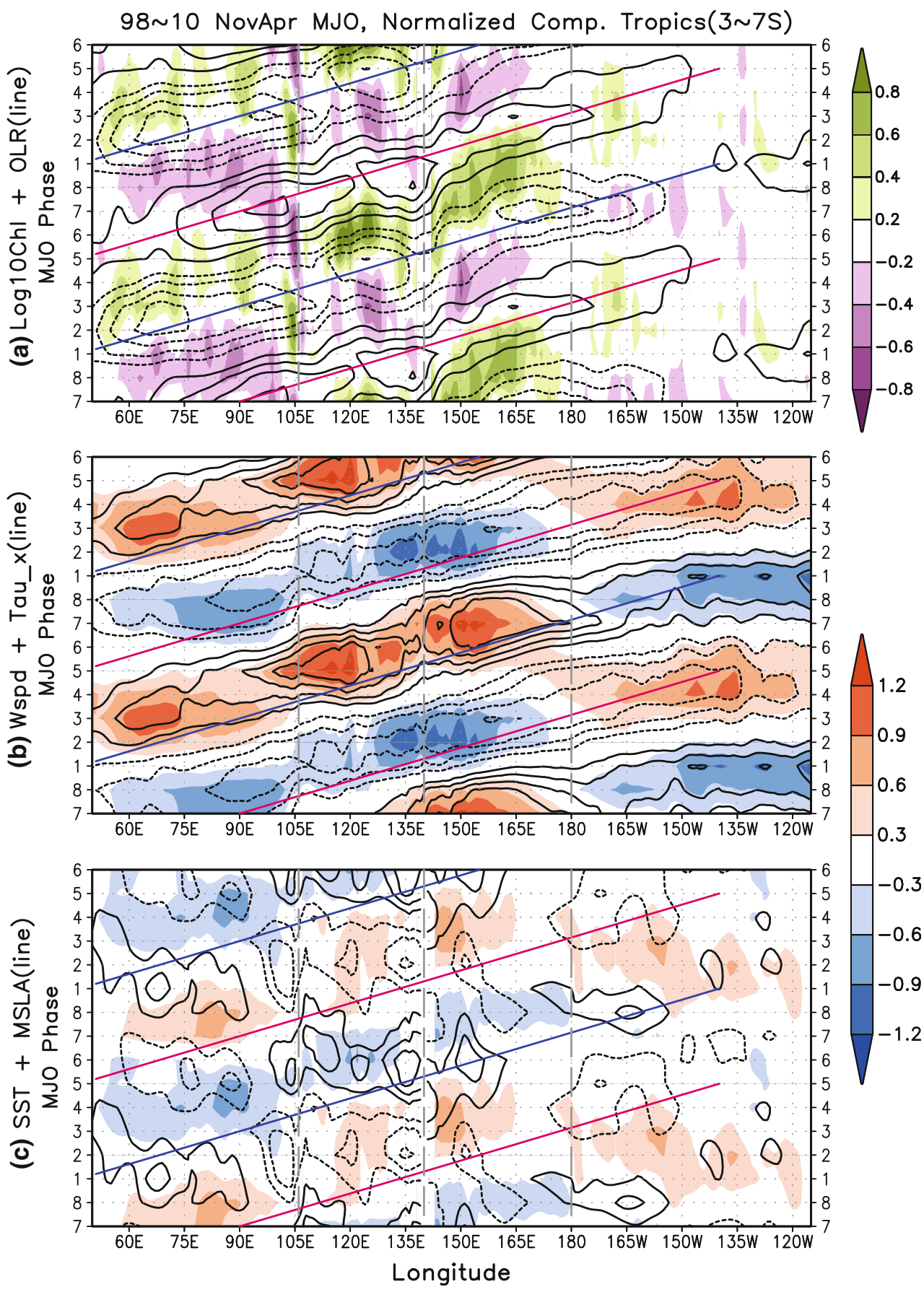

where the convection anomalies have already vanished. In this far eastern region, warmer SST anomalies are shown to be likely due to reduced wind speed while cooler SST anomalies are not detected (Fig. 3c).

From the MJO Hovmöller diagrams, we can roughly estimate the temporal relationships among the variables, which provide some hint of dynamical cause and effect. However, it is hard to quantify the details of the time lag relationships between variables. In addition, the MJO does not always oscillate in the same manner for all events, so the temporal relationship from the MJO composite analysis may include some artifacts. Thus, we calculate and present another form of temporal analysis, i.e., a lead-lag correlation analysis, in Fig. 4 in order to better quantify the MJO phase relationships. The correlations are calculated grid point by grid point, so the local temporal relationships are examined.

As mentioned in the Introduction, upwelling and entrainment are the two key mechanisms causing nearsurface Chl blooms. Figure 4 shows that, along all longitudes west of the Dateline, wind speed anomalies which represent the entrainment process are positively correlated 
Fig. 4 Lead-Lag correlations for boreal winter (NovemberApril) MJO days along the path of the MJO convections $\left(3^{\circ}-7^{\circ} \mathrm{S}\right.$ meridional mean) a between Log10Chl and Wind speed (shaded), zonal wind stress (purple contour), or SST (green contour), and $\mathbf{b}$ between Log10Chl and Wind speed (shaded, same as the top panel), OLR (purple contour), or MSLA (green contour) are shown. Contour line intervals are same as the shaded intervals, and solid and dash contour lines indicate positive and negative values, respectively. The relative locations of gray dash lines are same as those in Fig. 3

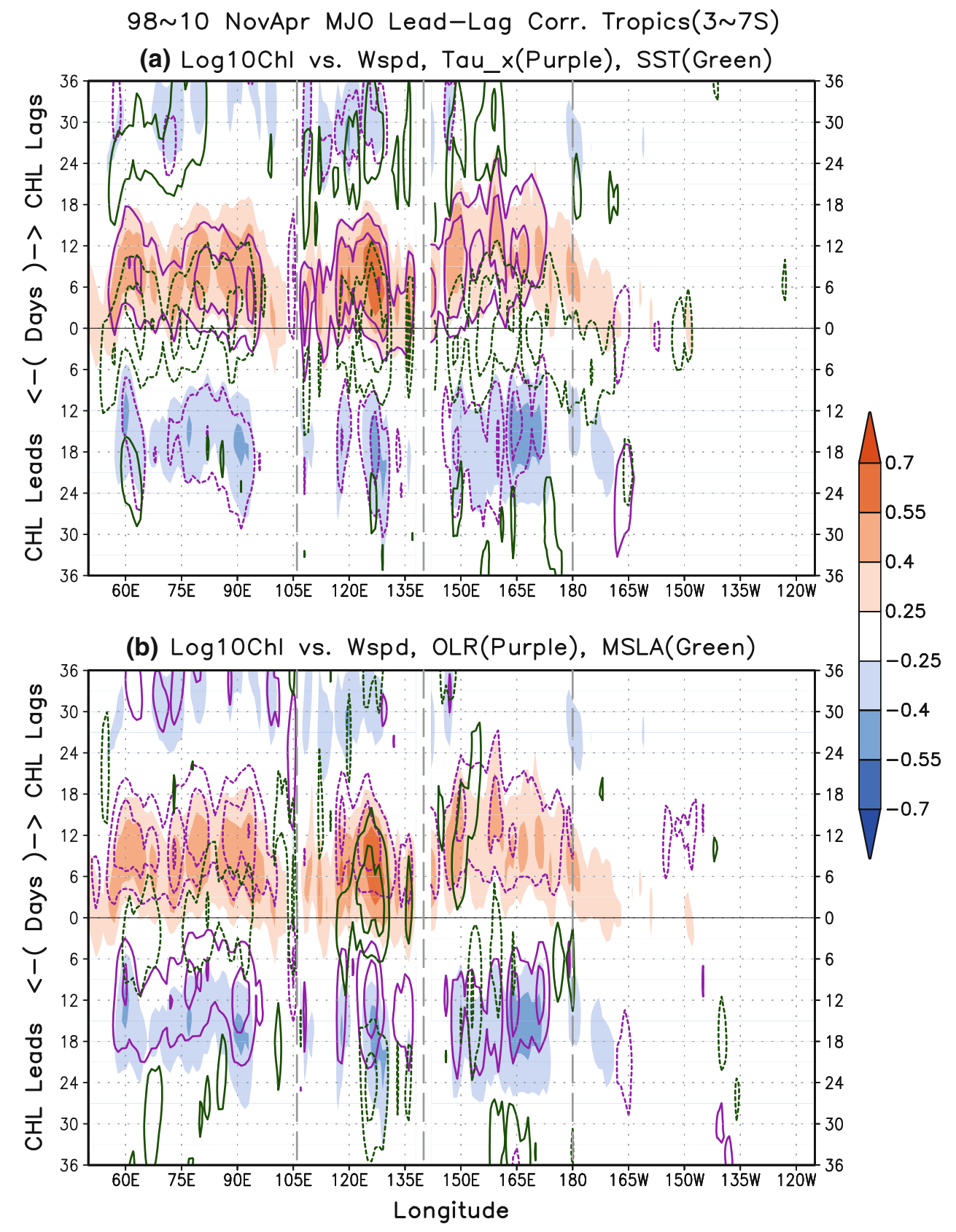

with $\log 10 \mathrm{Chl}$ when they lead Chl by 6-12 days. This result is consistent in the temporal sense with the MJO phase composite shown in Fig. 3 (and with the cursory phase relationships between wind and Chl in WET05). Hence, it is reasonable to argue that entrainment definitely contributes to the Chl variability in this region. On the other hand, the role of upwelling is unclear. In the equatorial open ocean, Ekman pumping by wind stress curl does not work well because of weak Coriolis effects. Instead, Equatorial upwelling by westward zonal wind stress and the associated Ekman divergence can dominate (e.g., Wyrtki 1981) due to the opposite sign of the Coriolis parameter across the equator. Figure 4 indicates that zonal wind stress is positively correlated with and temporally precedes Chl, similar to the wind speed anomalies. The positive correlation means that westerly winds precede enhanced $\mathrm{Chl}$ presence, and this can appear counter-intuitive because westerly wind results in equatorial convergence and downwelling. Considering the latitudes of meridional mean $\left(3^{\circ}-7^{\circ} \mathrm{S}\right)$, it is possible that meridional advection of nutrients or of Chl itself, which is asswociated with equatorial converge/diverge, can affect the Chl variability. This hypothesis will be investigated with numerical models in a future work.

Wind speed is closely related with the Chl variability, but the distribution of correlation coefficients is not zonally 
uniform. In terms of magnitude, the correlation coefficients over 0.55 are only detected around the Maritime Continent. In this region, one reason for the strong correlations is that the anomaly composite of wind speed is relatively strong (Fig. 3b), and the other reason is that the ocean depth is relatively shallow. Resplandy et al. (2009) suggested that, in the southern tropical Indian Ocean, interannual variability of thermocline depth can affect the near-surface $\mathrm{Chl}$ variability under MJO forcing. It is likely that the relatively shallow ocean depth can also help maintain a constant relationship between wind speed and $\mathrm{Chl}$. It is also possible that the MJO modulation of $\mathrm{Chl}$ is enhanced by precipitation in this region. Additional precipitation around the MJO convection can discharge additional nutrients to the coast of the Maritime Continent, and result in increased concentration of Chl.

The oceanic vertical profile can affect not only the magnitude but also the lead time of the peak correlation. In Fig. 4 around the Dateline, the lead time of wind speed$\log 10 \mathrm{Chl}$ correlation peak decreases from 12 days $\left(160^{\circ} \mathrm{E}\right)$ to 3 days $\left(175^{\circ} \mathrm{W}\right)$. It is well known that the thermocline shoals in this region as one transits eastward. Hence, it may be understood that the time lag from the onset of wind forcing to entrainment to $\mathrm{Chl}$ bloom is less when the thermocline depth is shallower, although composite anomalies of $\mathrm{Chl}$ around the Dateline are weak.

In addition to the wind forcings, SST is generally simultaneously and negatively correlated with $\log 10 \mathrm{Chl}$. Considering the mechanisms like entrainment or upwelling, it is reasonable that the bloom of $\mathrm{Chl}$ accompanies the cooler SST, although the cooler SST does not always accompany the bloom of Chl. This is because SST can also be affected by the sea surface heat flux, and larger wind speed enhances not only the oceanic turbulent mixing, but also the heat transfer from the ocean to the atmosphere by latent and sensible heat flux. In the case of MSLA, it is also notable that they are positively correlated with $\mathrm{Chl}$ around the Maritime Continent when MSLA leads Log10Chl by about 3 days. The MSLA in this region can be affected by coastal Kelvin waves at MJO time-scales (Zhou and Murtugudde 2010), so this correlation between MSLA and Chl might not be because of direct dynamical connection.

Lastly, it is worth to noting the contrasts between lead and lag correlation coefficients. In Fig. 4a, we noted above that negative correlations between SST and Log10Chl are nearly simultaneous. In the case of positive correlations, those when SST leads $\log 10 \mathrm{Chl}$ are much stronger than those when Log10Chl leads SST. Generally the opposite sign of correlation coefficients occurring before or after 24-30 days can be understood as a periodically repeating feature of the MJO. However, if this is the case, the positive correlations of SST, which appear before and after the simultaneous negative correlations, should be nearly- symmetric along the lead-lag time. Here the previous SST is more correlated with $\log 10 \mathrm{Chl}$ than the subsequent SST. The effect of previous SST anomalies before the half period of the MJO is a reminder of the hypothesis suggested by Gildor et al. (2003). On the other hand, in the case of wind speed anomalies, the negative correlations when $\log 10 \mathrm{Chl}$ leads wind speed are strong enough to be compared to the corresponding positive correlations (when wind speed leads $\log 10 \mathrm{Chl}$ ), particularly in the western tropical Pacific (around $170^{\circ} \mathrm{E}$ ). In the same region, positive OLR correlations with $\log 10 \mathrm{Chl}$ when $\log 10 \mathrm{Chl}$ leads OLR are also stronger than those when $\log 10 \mathrm{Chl}$ lags behind OLR. These phenomena suggest potential local bio-feedbacks to the coming MJO convection. Details of this hypothesis will be discussed later.

In summary, along the path of boreal winter MJO convection, oceanic turbulent mixing by surface winds is generally the most closely related with the Chl variability, which is consistent with WET05. The details of how wind speed is related with Chl (e.g., correlation values and lead time of maximum correlation) vary depending on the region under consideration. Relatively strong relationships between $\mathrm{Chl}$ and other physical variables are also found when Chl leads or lags by $20-30$ days.

\subsection{View along the path of boreal summer MJO convection}

In this subsection, we analyze the meridional means $\left( \pm 2^{\circ}\right)$ along the diagonal line from $\left(60^{\circ} \mathrm{E}, 2^{\circ} \mathrm{N}\right)$ to $\left(180^{\circ} \mathrm{E}, 16^{\circ} \mathrm{N}\right)$ during the boreal summer season. The atmospheric MJO convection doesn't travel strictly along this diagonal line, although this diagonal region includes the southern Bay of Bengal and the South China Sea where oceanic response to the MJO is significant in this season (e.g., Sengupta et al. 2001a; Waliser et al. 2004). Thus, we expect that the choice of this region is a reasonable one for examining the effect of the MJO convection.

Figure 5 shows the results in a format analogous to Fig. 3, but for boreal summer. MJO related Chl variability is the strongest in the South China Sea. The southern Bay of Bengal also displays quite a strong variability while the northern tropical Pacific is the weakest region. Considering that the March of the MJO convection ends east of the Philippines, the Chl variability in the northern tropical Pacific is unlikely to be due to the direct effect of the MJO convection, as is the case for the boreal winter (Fig. 3). Wind speed and Tau_Curl signals are also strong in the Bay of Bengal and the South China Sea, so we expect oceanic vertical processes to be active and to drive $\mathrm{Chl}$ variability in these oceans (e.g., Duncan and Han 2009; Vialard et al. 2011; Waliser et al. 2004). In the bottom panel of Fig. 5, MSLA shows westward propagation that is 
Fig. 5 Same to Fig. 3 but for the boreal summer (MayOctober) MJO days, and meridional average inside the diagonal box shown in Fig. 2. In the center panel (b), zonal wind stress in Fig. 3 is replaced by curl of wind stress here (Tau_Curl, contour). Red and blue diagonal lines are approximately fitted to mark the peak signals of positive and negative OLR, respectively. From the left side, west of the first gray line is the southern Bay of Bengal, between two gray lines is the South China Sea, and east of the second gray line is the Philippines Sea and northern tropical Pacific
98 10 MayOct MJO, Normalized Comp. Diagonal
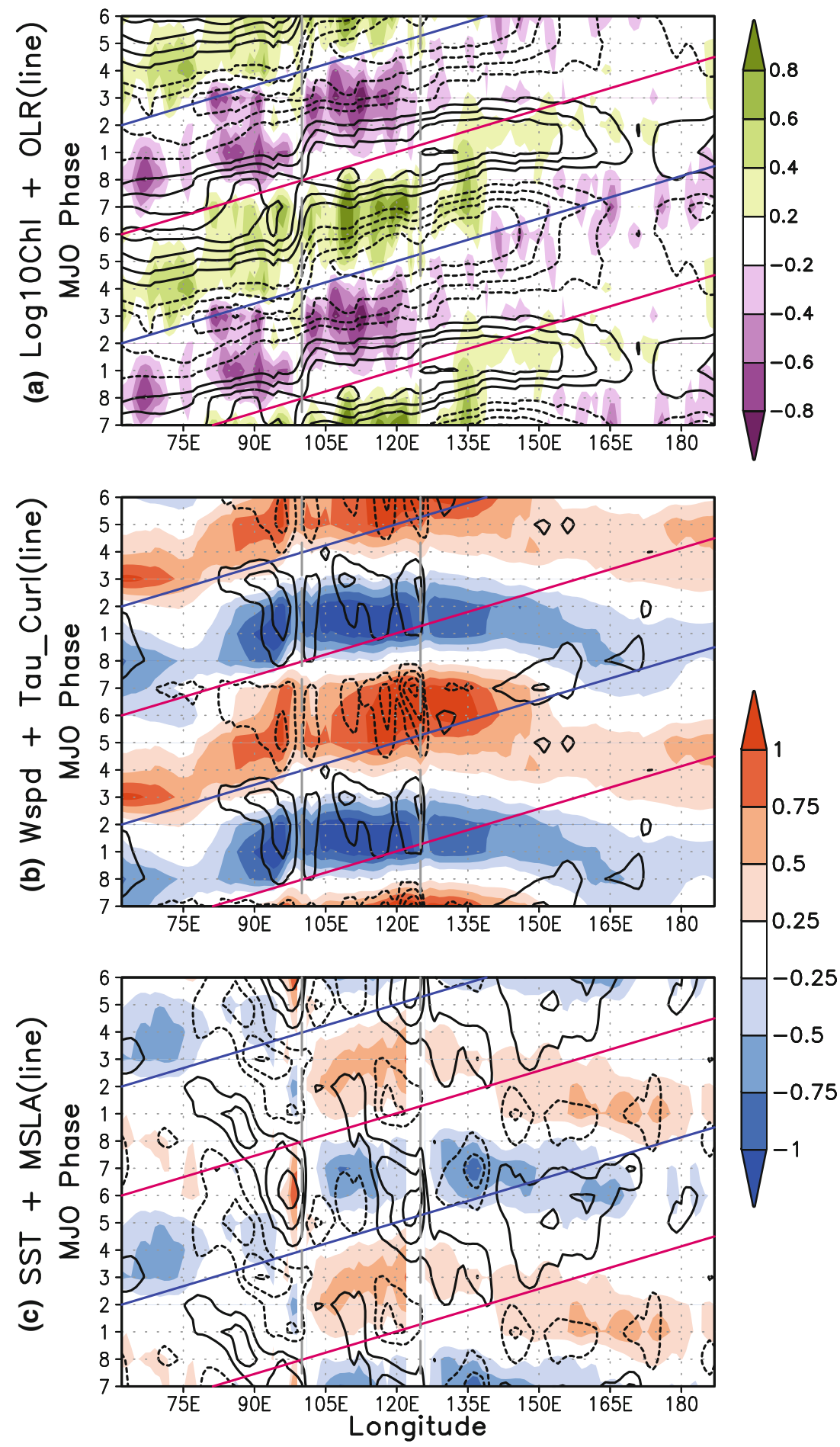

of slower speed than the MJO convection. This westward propagation, especially in the Indian Ocean basin, is the reflected Rossby wave from the impinging equatorial and following coastal Kelvin wave (e.g., Oliver and Thompson 2010; Vialard et al. 2009), which we confirmed from the MJO phase composite of MSLA (not shown, and nearly identical to Fig. 4 of Webber et al. (2010)).
Figure 6 is the boreal summer analog of Fig. 4, and shows the lead-lag correlation between Log10Chl and other variables for the MJO composite life cycle. Both Figs. 5 and 6 indicate that the basic relationship among variables is nearly identical to the results in the previous subsection. For example, the bloom of Chl occurs between the blue and subsequent red lines in Fig. 5a, so negative OLR anomaly 
Fig. 6 Same to Fig. 4 but for the boreal summer MJO days, meridional average in the diagonal box shown in Fig. 2. In the top panel (a), zonal wind stress in Fig. 4 is replaced by curl of wind stress here (purple contour). The gray line is of the same location with Fig. 5
98 10 MayOct MJO Lead-Lag Correlation, Diagonal

(a) Log10Chl vs. Wspd, Tau_Curl(Purple), SST(Green)
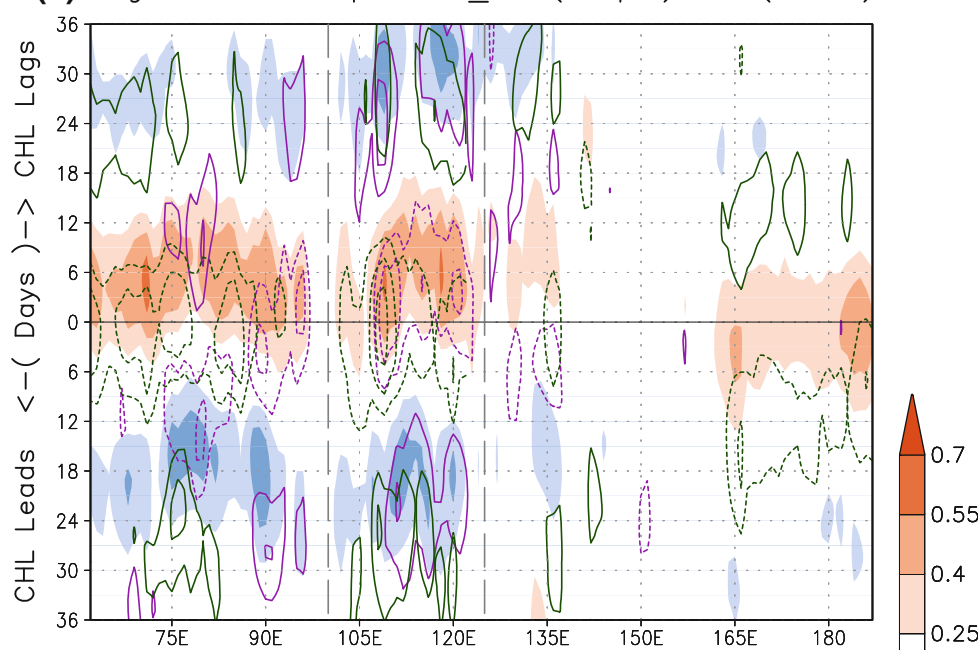

(b) Log10Chl vs. Wspd, OLR(Purple), MSLA(Green)

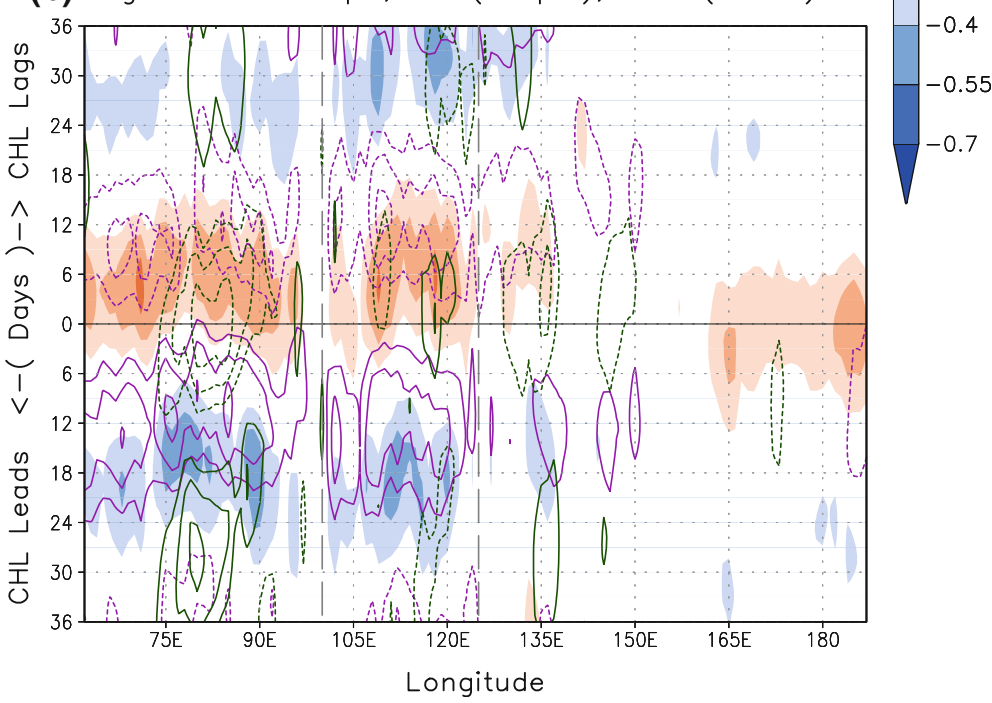

leads positive Log10Chl anomaly by approximately 2 MJO phases. Positive wind speed anomalies appear between negative OLR and positive $\log 10 \mathrm{Chl}$ anomalies (Fig. 6b). This relationship also holds in the opposite phase: positive OLR leads negative wind speed anomalies, which leads reduced Chl concentration. This relationship is apparent in the southern Bay of Bengal and the South China Sea. In the Philippines Sea, the strength of the relationship in terms of correlation coefficients is weaker than that in the western sector. In the northern tropical Pacific, east of the Philippines Sea, both the Log10Chl composite anomaly and any correlations between it and other variables are small.

A difference in this subsection from the boreal winter MJO is that the regions examined are further from the equator, so Ekman pumping by wind stress curl can be in effect. So for this case, Tau_Curl replaces Tau_x in Figs. 5 and 6. In this Northern Hemisphere, positive anomalies of Tau_Curl imply more upwelling. Figure 5b indicates that the Ekman pumping actively oscillates in the eastern Bay of Bengal and in the South China Sea, but two mechanisms, entrainment and upwelling, seem to offset each other. For example, both positive wind speed anomalies and negative Tau_Curl anomalies appear to be in play during MJO phases 5-7 in the South China Sea. Figure 6a also shows that positive correlations of wind speed overlap negative correlations of Tau_Curl when both wind variables slightly lead Log10Chl. This result suggests that the increased wind speed can induce the increased Chl concentration near sea surface despite the presence of oceanic anomalous downwelling; mixing and entrainment overwhelming the downwelling. Positive correlations of Tau_Curl with Log10Chl are mostly detected when Tau_Curl leads Log10Chl by 24-30 days in the South China Sea. We may hypothesize that about 24-30 days corresponds to the time from the initiation of wind forcing to 
nutrient upwelling near the surface and then a subsequent $\mathrm{Chl}$ bloom. However, this hypothesis is weakened by the fact that Tau_Curl anomalies don't persist for 24-30 days; rather their sign changes around 12-18-days lead time. It is also possible that the wind speed drives entrainment (lead time 0-12 days) of these upwelled nutrients by Tau_Curl (lead time 24-30 days) although this cooperating mechanism can not be confirmed in this study.

Nearly simultaneous negative correlations between Log10Chl and MSLA are also prominent in the central to eastern Bay of Bengal (Fig. 6b). In the sense of oceanic wave signals, negative MSLA means an upwelling Rossby wave, which is concurrent with the Chl growth. Because the SST is also nearly simultaneously and positively correlated with MSLA (not shown), it is possible that there is a dynamical link between oceanic waves and Chl variability. In the case of planetary Rossby waves, it is known that the wave signatures are well detected in the ocean color data, which implies close relationship between Rossby waves and Chl variability (Kawamiya and Oschlies 2001; Killworth et al. 2004; Sakamoto et al. 2004; Uz et al. 2001), although detailed mechanisms, e.g. horizontal advection, supply of nutrients or $\mathrm{Chl}$ itself from deeper ocean, differ among these studies.

In the previous subsection, we noted quite strong correlation coefficients with the Chl leading. In Fig. 6, similar phenomena also appear. For example, stronger correlations of OLR, wind speed and Tau_Curl when Log10Chl leads those variables by 6-24 days are prominent in the Bay of Bengal and the South China Sea. Compared to the correlations when $\log 10 \mathrm{Chl}$ lags by a few days, the sign of coefficients are opposite, and the absolute value is nearly similar and sometimes even larger when $\mathrm{Chl}$ leads. These correlations when Log10Chl leads other variables can be produced by the oscillatory nature of the MJO. For example, time durations between negative and positive peaks are approximately 24 days which are similar to the half period of the MJO oscillation, and those durations appear to be independent of longitude. Thus, it is more reasonable to conclude that the main cause of correlations led by $\mathrm{Chl}$ is most likely the oscillatory $\mathrm{MJO}$, not the $\mathrm{Chl}$ variability itself. However, it is also true that, around $75^{\circ} \mathrm{E}$, the negative correlations of wind speed led by $\log 10 \mathrm{Chl}$ (12-18 days lead time) are much stronger than the same negative correlations lagging behind wind speed (24-30 days lag time). Hence, we cannot exclude the potential role of $\mathrm{Chl}$ in amplifying the transition of the MJO to the opposite phase although the details of mechanism will have to be delineated.

Briefly, the relationships among $\mathrm{Chl}$ and other variables along the path of boreal summer MJO are generally identical to the counterpart of boreal winter MJO. In addition, a possibility of Chl feeding back to the MJO by amplifying the MJO transition is suggested.

\subsection{Northern tropics during boreal winter}

In this subsection, we examine the boreal winter MJO case in the northern tropical region (meridional mean from $11^{\circ} \mathrm{N}$ to $15^{\circ} \mathrm{N}$ ) where $\mathrm{Chl}$ variability is prominent in Fig. 1 . Figure 7 presents Hovmöller diagrams of the normalized composite anomalies by MJO phase. Here blue and red lines stand for inactive and active centers of the MJO convection, respectively, and the relative location of lines in each panel is same as that in Fig. 3.

In the previous subsections along the path of the MJO convection, it is noted that the Chl signals temporally occur between the blue and red lines. In Fig. 7a, Chl signals occur on the blue and red lines. Compared to Fig. 3a, Chl signals in these latitudes generally lag behind those on the equator by 2 MJO phases. In Fig. 7a, along the red or blue line, the sign of OLR anomalies reverses around the Dateline while the same sign of $\log 10 \mathrm{Chl}$ anomalies continuously appear. This suggests that light is not a limiting factor for the $\mathrm{Chl}$ variability in this region. In addition, the wind speed and Tau_Curl composite patterns are weak, sparse, and don't propagate steadily in Fig. 7b, compared to Figs. $3 b$ or $5 b$.

Figure 8 shows lead-lag correlations between Log10Chl and other variables for the MJO composite during boreal winter. Here strong correlations are mostly detected in the South China Sea and the northern tropical Pacific, consistent with Fig. 7a where composite anomalies of $\log 10 \mathrm{Chl}$ are relatively strong. In the South China Sea, the relationship between $\mathrm{Chl}$ and other variables are generally similar as the other oceans in the previous subsections. Wind speed leads Log10Chl by about 6 days, and SST shows simultaneously negative correlation with $\log 10 \mathrm{Chl}$ (Fig. 8a) although composite anomalies of winds are weak in Fig. 7b. One thing worth noting here is that upwelling process is on duty and cooperates with entrainment. The positive correlations of Tau_Curl are coincident with the positive correlations of wind speed when those variables lead Log10Chl commonly by about 6 days, in the western South China Sea and northern tropical Pacific. In the eastern part of the South China Sea, correlations of wind speed are prominent while those of Tau_Curl disappear.

To the east of the Philippines $\left(120^{\circ} \mathrm{E}\right)$ in Fig. $7 \mathrm{a}$, relatively strong positive $\mathrm{Log} 10 \mathrm{Chl}$ signals are clustered in the Philippine Sea, up to $150^{\circ} \mathrm{E}$ where the Mariana Islands are located while negative Chl signals are weak. Despite the strong positive Log10Chl signals, local correlations shown in Fig. 8 are weak in this Philippine Sea. The negative Log10Chl signals become stronger to the east of $150^{\circ} \mathrm{E}$ (northern tropical Pacific), and correlations also become stronger. In the northern tropical Pacific, conspicuous characteristic of correlations in Fig. 8 is that the lead time of wind speed, OLR, or Tau_Curl against Log10Chl is 
Fig. 7 Same to Fig. 5 but for the boreal winter MJO days, meridional mean in the northern tropics $\left(11^{\circ} \mathrm{N}-15^{\circ} \mathrm{N}\right)$. Here the MJO propagation guide lines (blue and red lines) are same lines as those shown in Fig. 3. From the left side, west of first gray dash line is the Arabian Sea, between the second and third gray lines is the Bay of Bengal, between the forth and fifth gray lines is the South China Sea, and east of the fifth gray line is the Philippines Sea and northern tropical Pacific
98 10 NovApr MJO, Normalized Comp. N.Trop(11 15N)
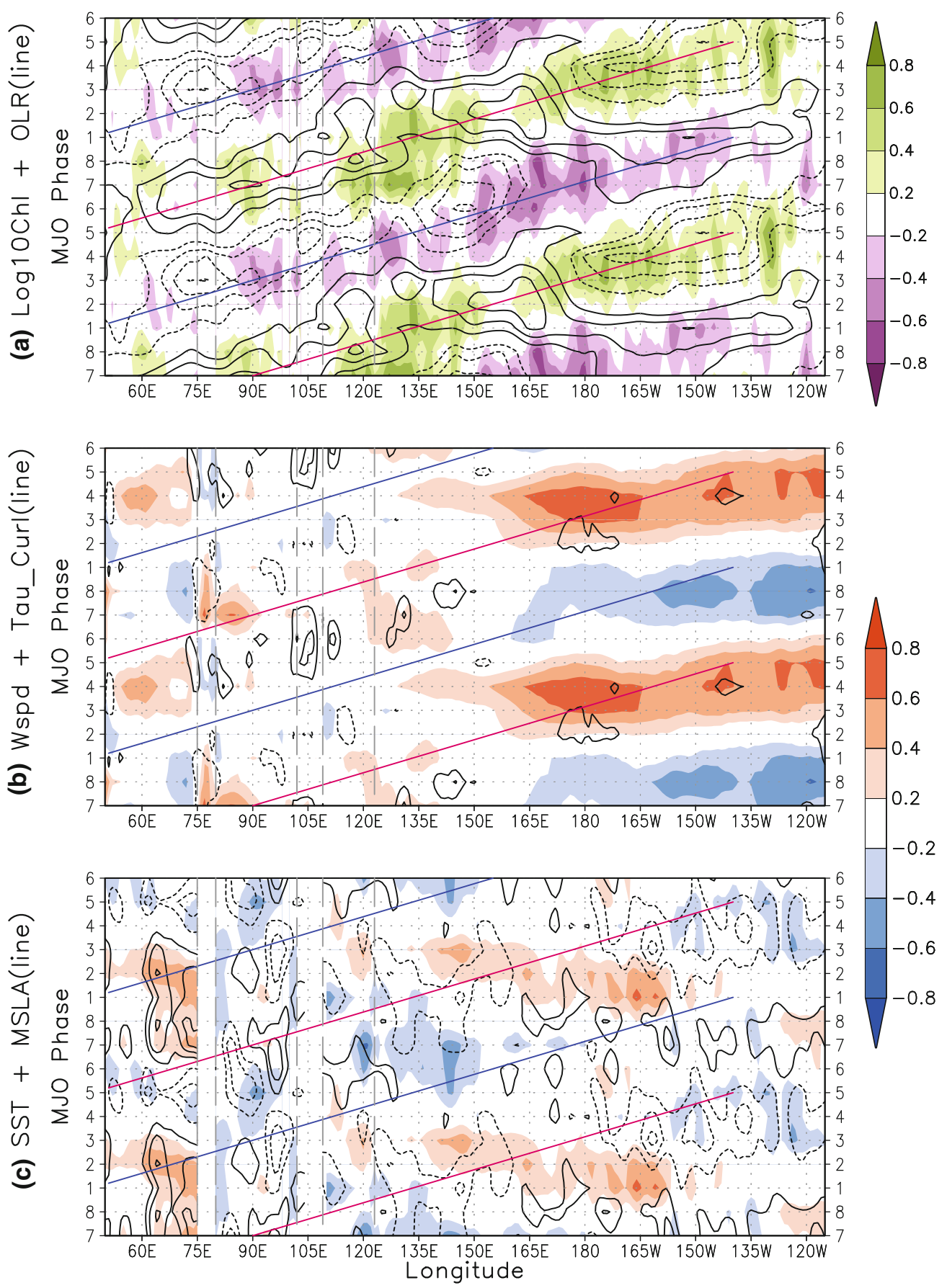

pretty short, i.e., just a few days. Especially to the east of the Dateline, the temporal phase of Log $10 \mathrm{Chl}$ even precedes that of SST by about 6 days. Considering that the climatological mixed layer depth in this region in boreal winter is relatively deep $(\sim 100 \mathrm{~m})$, this kind of quick response of $\mathrm{Chl}$ is exceptional. It is possible that subsurface (deep) phytoplankton maxima is detected by the satellite sensor after mixing/upwelling, not through the process of nutrition supply and near-surface Chl response. Clearly, this conjecture can not be tested in this study without relevant subsurface data. In the case of OLR, simultaneous negative correlations with $\log 10 \mathrm{Chl}$ are consistent with the argument mentions above that the light is not limiting the Chl variability in this region. 
Fig. 8 Same to Fig. 6 but for the boreal winter MJO days, meridional mean in the northern tropics $\left(11^{\circ} \mathrm{N}-15^{\circ} \mathrm{N}\right)$. The gray dash line is of the same location with Fig. 7
98 10 NovApr MJO Lead-Lag Corr. N.Trop(11 15N)

(a) Log10Chl vs. Wspd, Tau_Curl(Purple), SST(Green)

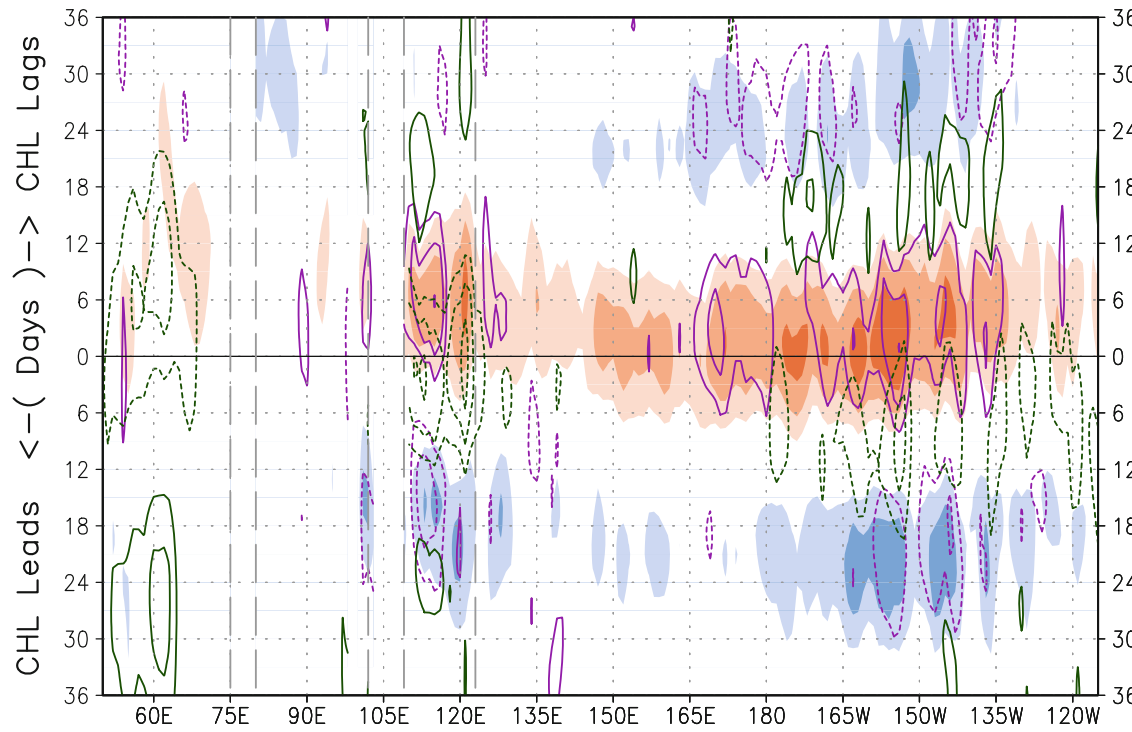

0.7 0.55

(b) Log10Chl vs. Wspd, OLR(Purple), MSLA(Green)

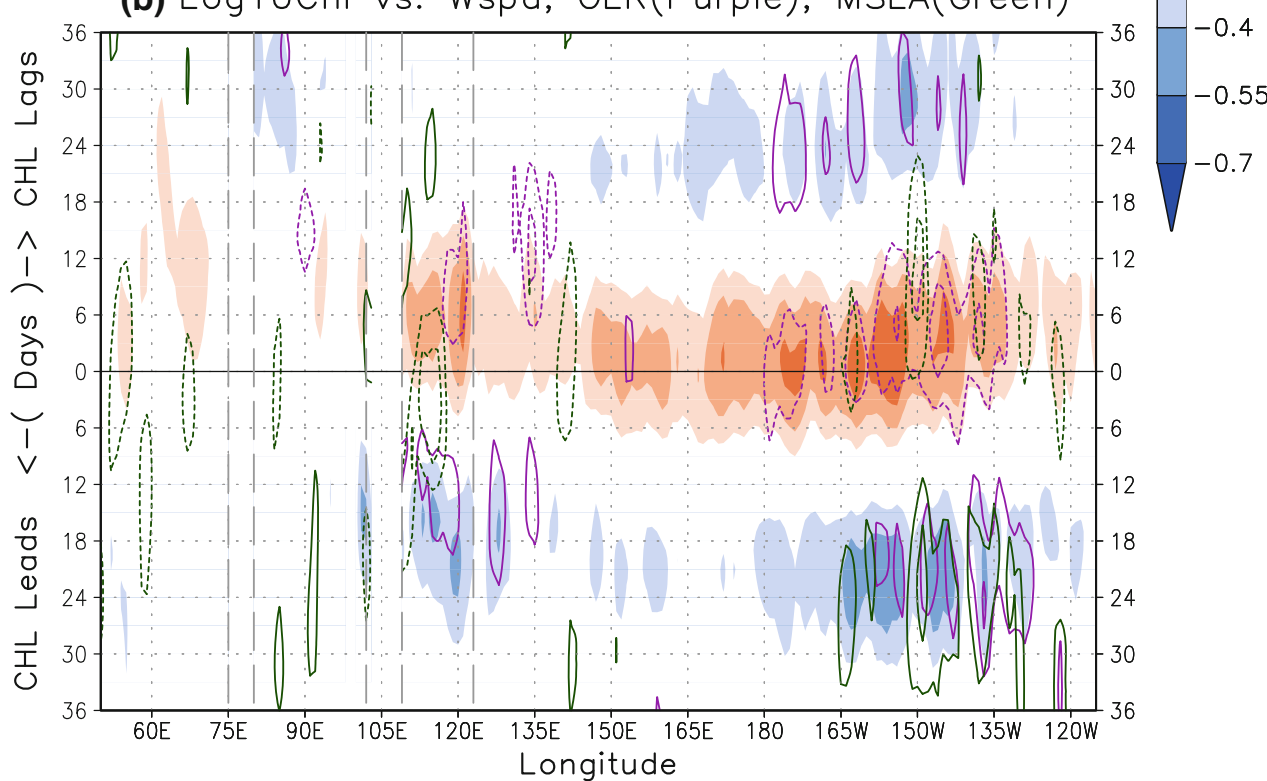

The strong correlations when $\log 10 \mathrm{Chl}$ leads other variables by about 20 days are another characteristic in the northern tropical Pacific. Detailed arguments about this phenomenon are basically same to those in the previous subsection. One thing we emphasize here is that the correlations when $\log 10 \mathrm{Chl}$ leads for about 24 days are stronger than those lagged by $\log 10 \mathrm{Chl}$ for about similar 24 days. Hence, this is an additional support for the hypothesis that $\mathrm{Chl}$ can amplify the transition to the subsequent opposite phase of MJO.
In summary, the atmospheric forcing which is necessary for ocean dynamics to supply additional nutrients to the near sea surface is far from an organized pattern compared to the region along the path of the MJO convection, so the relationships between $\mathrm{Chl}$ and other physical variables are more complex. In the northern tropical Pacific, the temporal occurrence of $\log 10 \mathrm{Chl}$ anomaly relative to the physical variables is quite rapid compared to that in other regions of the Indo-Pacific Ocean. A clue for the role of $\mathrm{Chl}$ in bridging to a subsequent MJO transition is also fairly evident. 


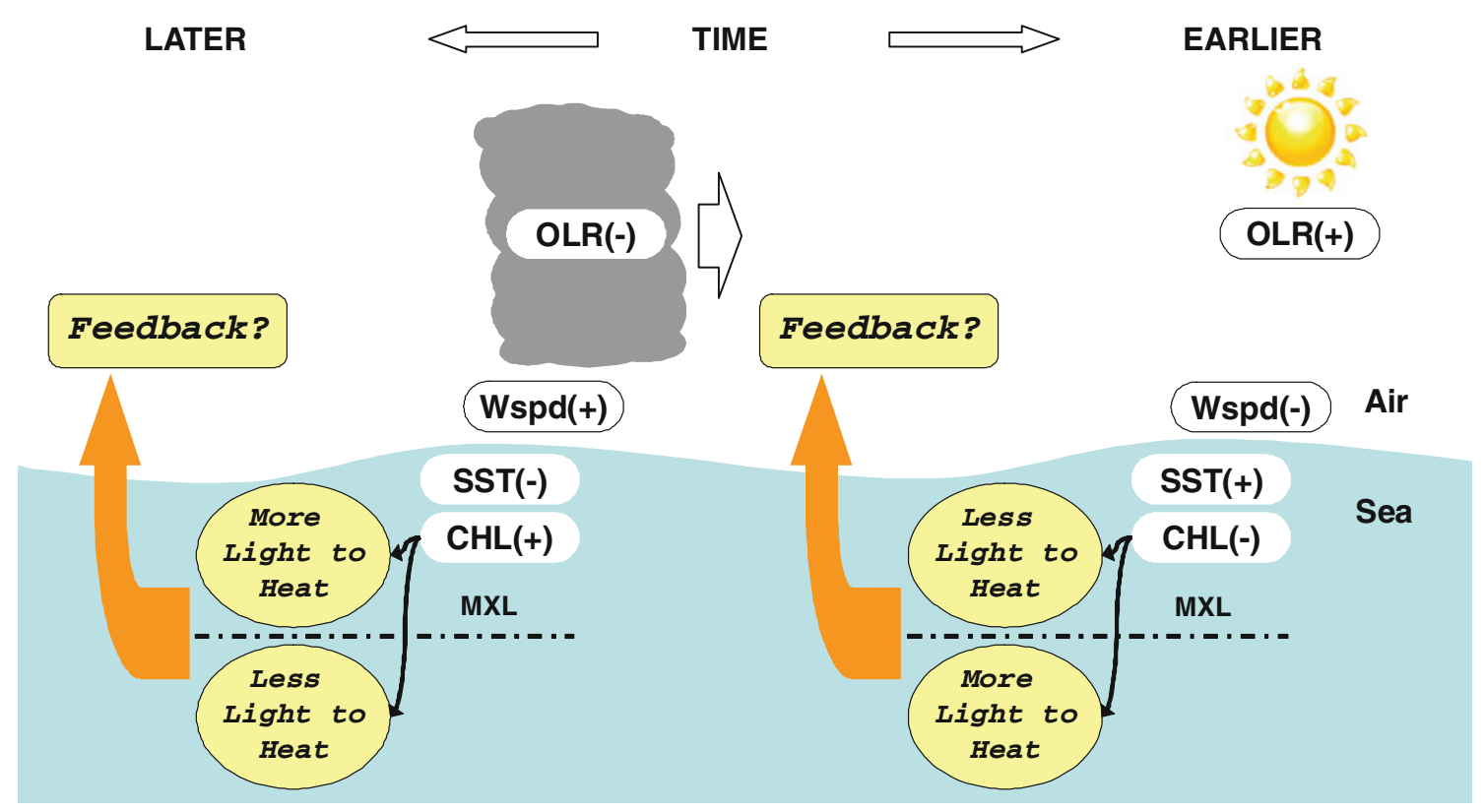

Fig. 9 A schematic representation of the MJO and bio-physical feedback, shown as a cross-section along the path of the MJO convection. (+) or (-) indicate sign of anomalies, and "Wspd" indicates wind speed

\section{Summary and conclusion}

The effect of the MJO on the near surface oceanic ecosystem in the Tropics has been examined. It is known that the MJO displays a strong seasonality and hence MJO composites are separated into boreal winter (NovemberApril) and summer (May-October). In each season's composite, the large-scale pathway of the MJO convection is different, but the general relationships among $\mathrm{Chl}$ and other physical variables are consistent along the path of the MJO convection. Figure 9 shows schematic illustration of that relationship. Simply put, following the passage of the MJO convection (negative OLR anomalies, left side in Fig. 9), wind speed increases to its peak as a part of atmospheric MJO signature and results in enhanced $\mathrm{Chl}$ concentration as well as cooler SST. The reverse of this sequence also occurs, i.e., clearer sky (positive OLR) leads the lowest wind speed, which leads reduced Chl concentration and warmer SST. In addition to the entrainment process by wind speed, the effect of Ekman pumping on the Chl variability is also examined, but the role of Ekman pumping is unclear along the path of the MJO convection.

Ocean regions outside the trajectory of the MJO convection are also examined. In this case, the MJO modulation of $\mathrm{Chl}$ is not as obvious as those directly affected by the MJO convection. This is because, the MJO forcing itself varies and the oceanic structure is distinctly different at different locales. In the northern tropical latitudes, winds (speed and curl of stress) and OLR composite signals are weak and do not propagate continuously. In addition, the oceanic characteristics, for instance in the northern tropical
Pacific in boreal winter, differ from other regions of the Indo-Pacific in terms of the mixed layer variability, the mixed layer-thermocline interactions and thus nutrient entrainment processes. As a result, the lag time of the positive correlations between winds (speed and curl of stress) and $\log 10 \mathrm{Chl}$ is close to 0-lag day in this northern tropical Pacific.

Briefly speaking, wind speed is the key factor regulating the Chl variability in the MJO regime, which is consistent with WET05. Upwelling by Ekman pumping also contributes to the $\mathrm{Chl}$ variability in limited regions. In addition to this qualitative conclusion, this study also quantified the temporal relationships among $\mathrm{Chl}$ and physical variables, which was not reported in WET05.

As mentioned in the Introduction, another motivation for this study was to explore the biological feedbacks from MJO-driven Chl variability back to the MJO itself. The local lead-lag correlation analysis brings some tentative evidence of such bio-physical feedbacks as inferred by a number of significant correlation coefficients when Chl leads other variables. We know that correlations do not necessarily imply causality, and the oscillatory nature of the MJO may affect aspects of those correlations. Other oceanic intraseasonal variabilities also may alias into the MJO composite. However, during certain times and locations, the correlations with Chl leading other variables by about a half period of the MJO are much stronger than those when Chl lags behind by about a half period of the MJO. For example, wind speed, Tau_Curl, and OLR correlations with $\log 10 \mathrm{Chl}$ in the central northern tropical Pacific are stronger when Chl leads by 18-24 days than 
when Chl lags by 24-30 days (Fig. 8). These results are not simply explained by the fact that the MJO is an oscillation. Hence we can not exclude the possibility of an "ecosystem bridge" connecting phase transitions of the MJO.

The hypothesis of an "ecosystem bridge" means that after the chain of processes mentioned above, from positive OLR to negative $\mathrm{Chl}$ anomalies near sea surface, a clearer ocean facilitates larger loss of shortwave radiation to the subsurface ocean (shaded circles left of CHL(-) in Fig. 9; e.g., Lewis et al. 1990; Siegel et al. 1995; Murtugudde et al. 2002). As a result, the heat content of the upper ocean increases. In addition, the short wave energy deposited below the mixed layer can remain longer in the ocean than the short wave energy absorbed in the mixed layer. This is because the anomalous energy in the mixed layer can be more effectively dissipated by air-sea interaction compared to the energy below the mixed layer. We presume that the increased heat content of the ocean column can then contribute to the subsequent opposite phase of the MJO, i.e., convection in this example after 3-4 weeks (Fig. 9 upward orange arrow on right). After all, this hypothesis emphasizes the role of the ecosystem to amplify the strength of the opposite MJO phase, not to actively cause the opposite phase of the MJO itself.
Unfortunately, this hypothesis could not be tested in this study due the limitation of data. Specifically without oceanic data such as thermocline/mixed layer depths, the mechanism of how the MJO interacts with Chl is hardly robust. We are investigating these details in forced ocean and coupled climate models in order to confirm the hypothesis suggested here, and the results will be reported in a future study.

Acknowledgments DJ, RM, and DW acknowledge support from NASA PO grant NNX09AF43G. RM acknowledges the support by the Divecha Center for Climate Change and IITM-Pune for their support and hospitality. DW's contribution to this study was carried out on behalf of the Jet Propulsion Laboratory, California Institute of Technology, under a contract with the National Aeronautics and Space Administration. RM also acknowledges the ONR DYNAMO grant.

Open Access This article is distributed under the terms of the Creative Commons Attribution License which permits any use, distribution, and reproduction in any medium, provided the original author(s) and the source are credited.

\section{Appendix}

See Figs. 10, 11, and 12 .
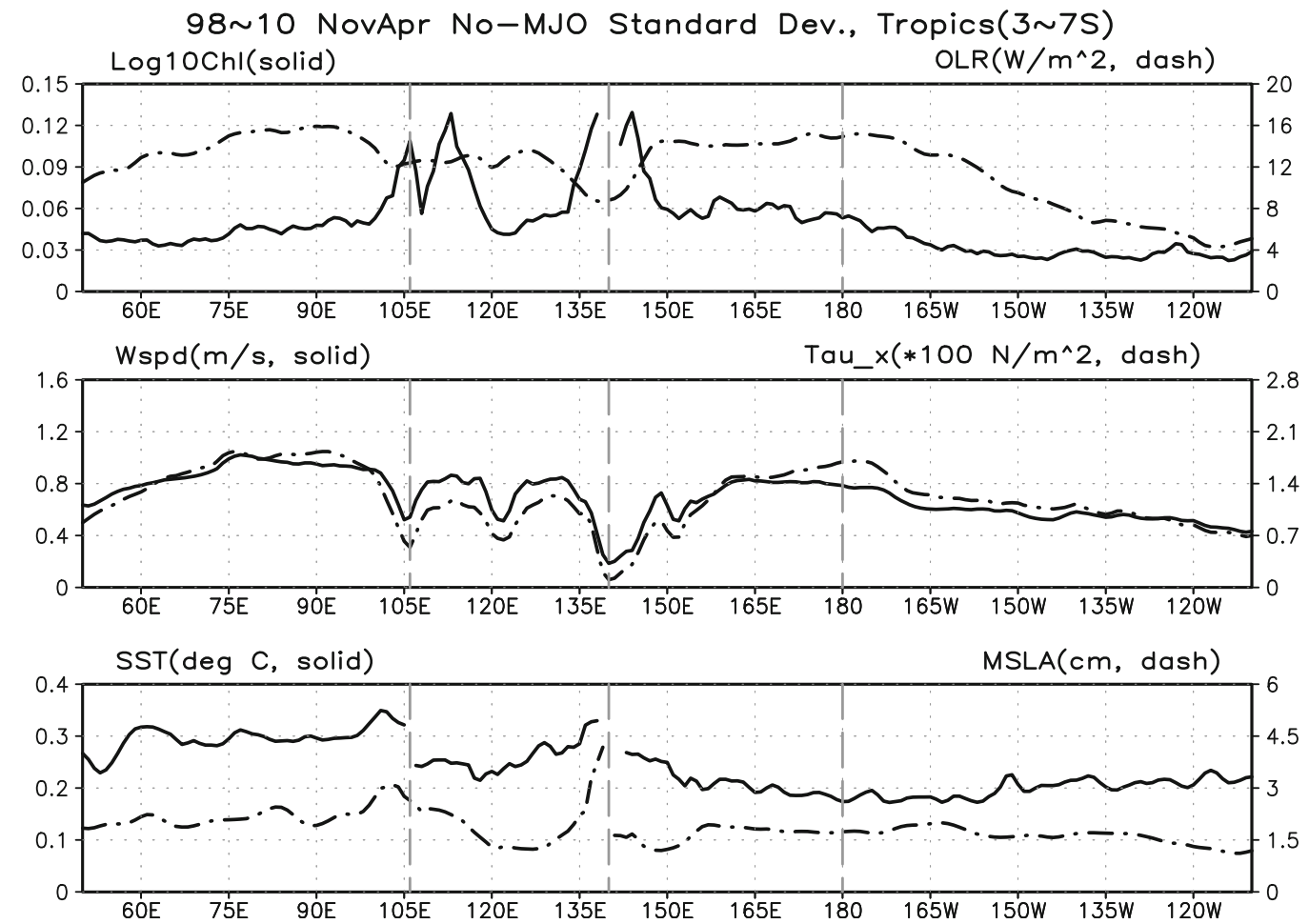

Fig. 10 Boreal winter No-MJO composite standard deviations in the tropical band $\left(3^{\circ}-7^{\circ} \mathrm{S}\right)$ are shown. Variables are (Top) Log10Chl (solid, left axis) and OLR (dash, right axis), (Middle) wind speed (solid, left axis), and zonal wind stress (dash, right axis), and (bottom)
SST (solid, left axis) and MSLA (dash, right axis). In the case of $\log 10 \mathrm{Chl}, 0.05$ is interpreted as approximately $12 \%$ increased concentration. The relative location of grey dash line is same as Fig. 3 
98 10 MayOct No-MJO Standard Deviation, diagonal
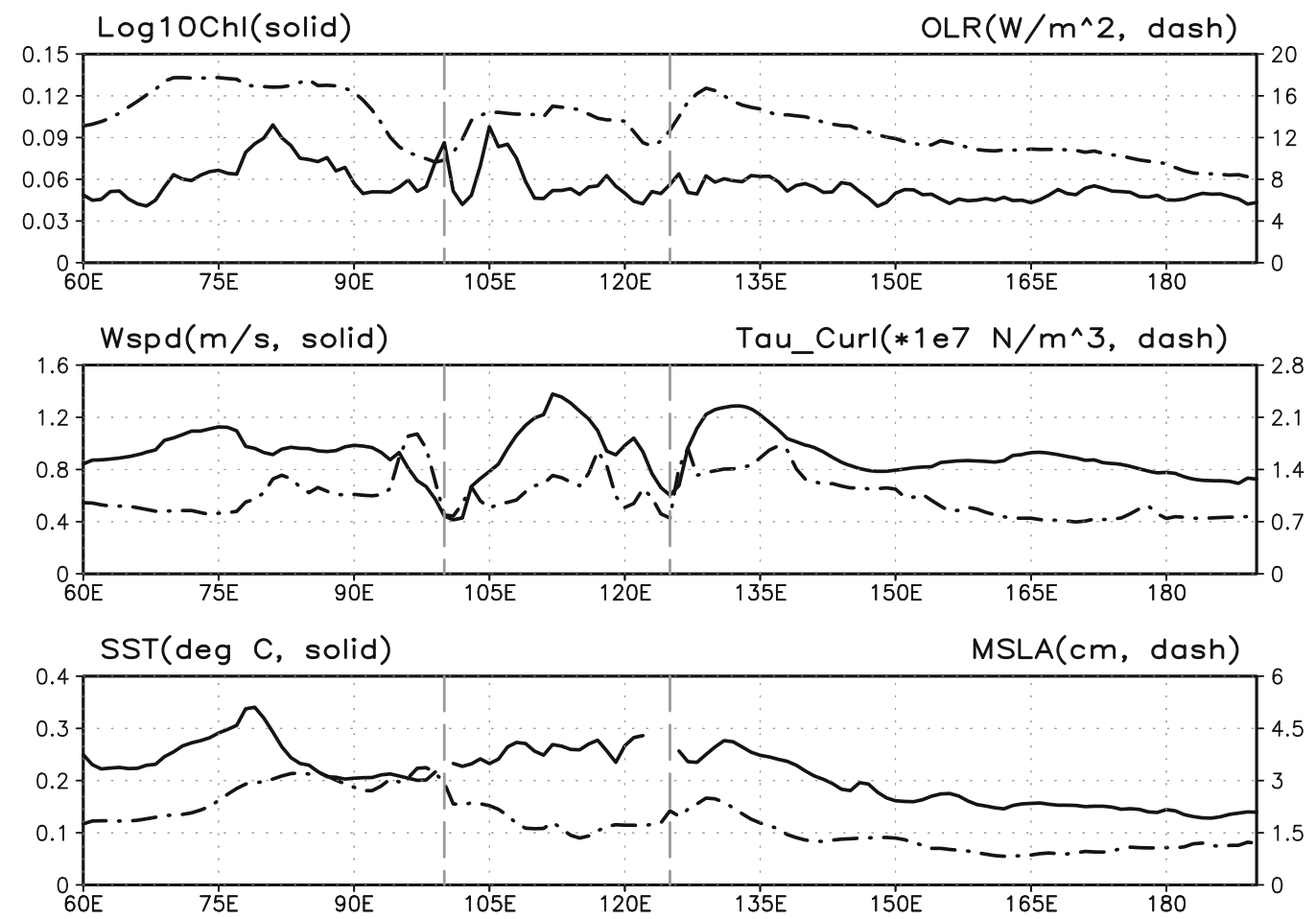

Fig. 11 Same to Fig. 10, but for the boreal summer season in the diagonal box shown in Fig. 2, and curl of wind stress replacing zonal wind stress in the middle panel of Fig. 10. The relative location of grey dash line is same as Fig. 5

98 10 NovApr No-MJO Standard Dev., N.Trop(11 15N)
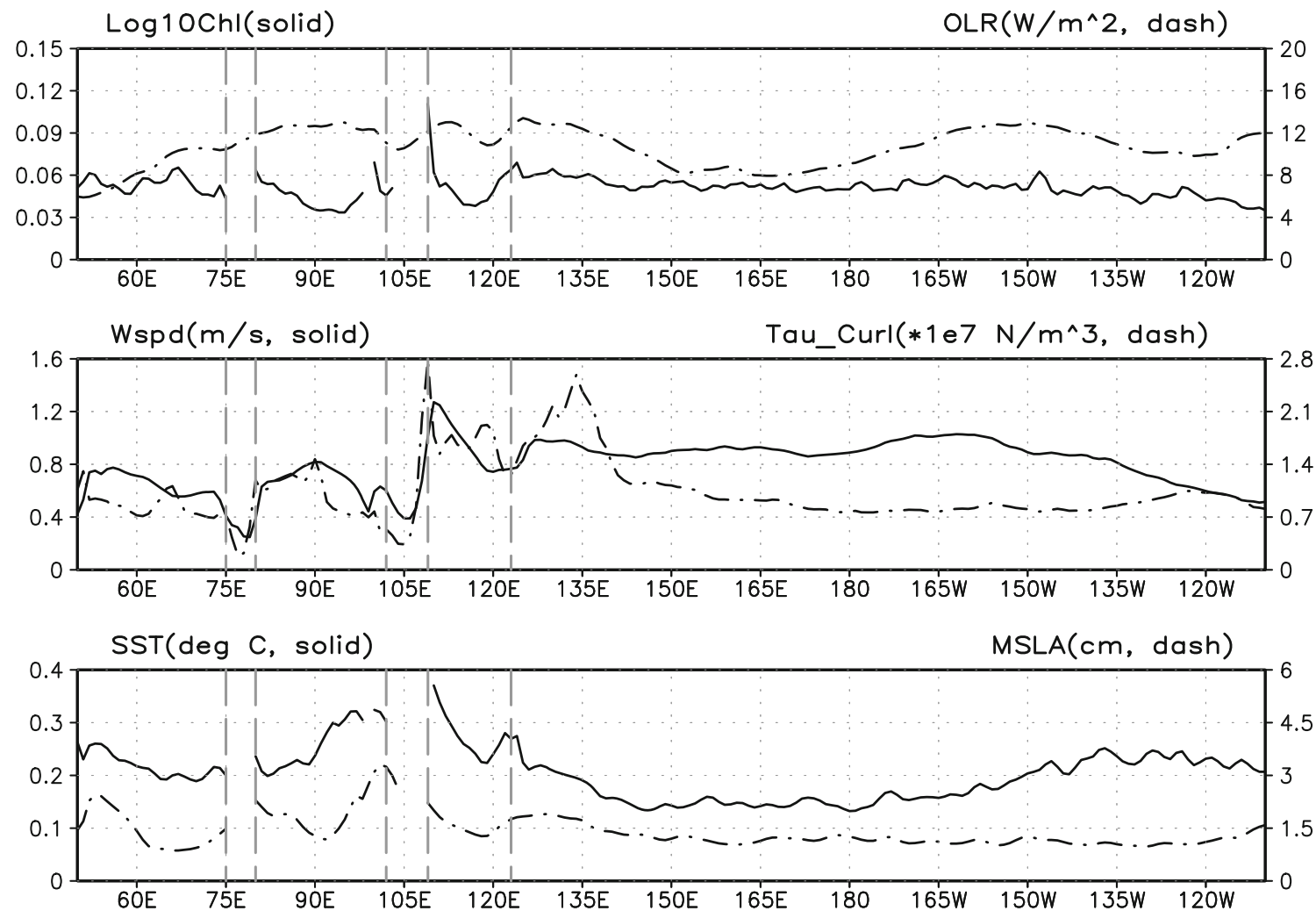

Fig. 12 Same to Fig. 11, but for the boreal winter season on the northern tropical band $\left(11^{\circ}-15^{\circ} \mathrm{N}\right)$. The relative location of grey dash line is same as Fig. 7 


\section{References}

Atlas R, Hoffman RN, Bloom SC (1996) A multiyear global surface wind velocity dataset using SSM/I wind observations. Bull Am Meteor Soc 77:869-882. doi:10.1175/1520-0477(1996)077 $<0869$ :AMGSWV>2.0.CO;2

Campbell JW (1995) The lognormal distribution as a model for biooptical variability in the sea. J Geophys Res 100:13237-13254

Duchon CE (1979) Lanczos filtering in one and two dimensions. J Appl Meteor 18:1016-1022. doi:10.1175/1520-0450(1979)018 $<1016$ :LFIOAT>2.0.CO;2

Duncan B, Han W (2009) Indian Ocean intraseasonal sea surface temperature variability during boreal summer: Madden-Julian Oscillation versus submonthly forcing and processes. J Geophys Res 114:C05002

Enfield DB (1987) The Intraseasonal Oscillation in Eastern Pacific Sea Levels: How Is It Forced? J Phys Oceanogr $17: 1860-1876$

Fu L-L (2007) Intraseasonal Variability of the Equatorial Indian Ocean Observed from Sea Surface Height, Wind, and Temperature Data. J Phys Oceanogr 37:188-202

Gildor H, Sobel AH, Cane MA, Sambrotto RN (2003) A role for ocean biota in tropical intraseasonal atmospheric variability. Geophys Res Lett 30:1460

Gnanadesikan A, Emanuel K, Vecchi GA (2010) How ocean color can steer Pacific tropical cyclones. Geophys Res Lett 37:L18802

Halkides DJ, Lucas LE, Waliser DE (2011) Mechanisms controlling mixed-layer temperature variability in the eastern tropical Pacific on the intraseasonal timescale. Geophys Res Lett 38:L17602

Han W, Lawrence DM, Webster PJ (2001) Dynamical response of equatorial Indian Ocean to intraseasonal winds: Zonal Flow. Geophys Res Lett 28:4215-4218

Hendon HH (2005) Air-sea interactions. Intraseasonal variability in the atmosphere-ocean climate system. Springer, Heidelberg, pp 223-246

Hendon HH, Glick J (1997) Intraseasonal air-sea interaction in the tropical Indian and Pacific Oceans. J Clim 10:647-661

Hendon HH, Liebmann B, Glick JD (1998) Oceanic Kelvin waves and the Madden-Julian Oscillation. J Atmos Sci 55:88-101

Isoguchi O, Kawamura H (2006) MJO-related summer cooling and phytoplankton blooms in the South China Sea in recent years. Geophys Res Lett 33:L16615. doi:10.1029/2006GL027046

Jin D, Kirtman BP (2009) The impact of ENSO periodicity on North Pacific SST variability. Clim Dyn 34:1015-1039. doi: 10.1007/s00382-009-0619-3

Jochum M, Yeager S, Lindsay K (2010) Quantification of the feedback between phytoplankton and ENSO in the community climate system model. J Clim 23:2916-2925. doi:10.1175/2010JC LI3254.1

Jones C, Carvalho LMV (2009) Stochastic simulations of the Madden-Julian Oscillation activity. Clim Dyn 36:229-246. doi: 10.1007/s00382-009-0660-2

Kahru M, Gille ST, Murtugudde R (2010) Global correlations between winds and ocean chlorophyll. J Geophys Res. doi:10.1029/ 2010JC006500

Kawamiya M, Oschlies A (2001) Formation of a basin-scale surface chlorophyll pattern by Rossby waves. Geophys Res Lett 28:4139-4142

Kessler WS, McPhaden MJ, Weickmann KM (1995) Forcing of intraseasonal Kelvin waves in the equatorial Pacific. J Geophys Res 100:10613-10631

Killworth PD, Cipollini P, Uz BM, Blundell JR (2004) Physical and biological mechanisms for planetary waves observed in satellitederived chlorophyll. J Geophys Res 109:C07002
Lau K-M, Sui C-H (1997) Mechanisms of short-term sea surface temperature regulation: observations during TOGA COARE. J Clim 10:465-472

Lau WK-M, Waliser DE (2005) Intraseasonal variability in the atmosphere-ocean climate system. Springer, Berlin

Lengaigne M, Menkes C, Aumont O (2007) Influence of the oceanic biology on the tropical Pacific climate in a coupled general circulation model. Clim Dyn 28:503-516

Lewis MR, Cullen JJ, Platt T (1983) Phytoplankton and thermal structure in the upper ocean: consequences of nonuniformity in chlorophyll profile. J Geophys Res 88:2565-2570

Lewis MR, Carr M-E, Feldman GC (1990) Influence of penetrating solar radiation on the heat budget of the equatorial Pacific Ocean. Nature 347:543-545. doi:10.1038/347543a0

Liebmann B, Smith CA (1996) Description of a complete (interpolated) outgoing longwave radiation dataset. Bull Am Meteor Soc 77:1275-1277

Lucas LE, Waliser DE, Murtugudde R (2010) Mechanisms governing sea surface temperature anomalies in the eastern tropical Pacific Ocean associated with the boreal winter Madden-Julian Oscillation. J Geophys Res. doi:10.1029/2009JC005450

Madden RA, Julian PR (1971) Detection of a 40-50 day oscillation in the zonal wind in the tropical Pacific. J Atmos Sci 28:702-708

Madden RA, Julian PR (1994) Observations of the 40-50-day tropical oscillation-a review. Mon Weather Rev 122:814-837

Manizza M, Le Quéré C, Watson AJ, Buitenhuis ET (2008) Ocean biogeochemical response to phytoplankton-light feedback in a global model. J Geophys Res. doi:10.1029/2007JC004478

Marzeion B, Timmermann A, Murtugudde R, Jin F-F (2005) Biophysical feedbacks in the tropical Pacific. J Clim 18:58-70

McClain CR, Feldman GC, Hooker SB (2004) An overview of the SeaWiFS project and strategies for producing a climate research quality global ocean bio-optical time series. Deep Sea Res Part II Topical Stud Oceanograph 51:5-42. doi:10.1016/j.dsr2.2003. 11.001

McCreary JP, Murtugudde R, Vialard J (2009) Biophysical processes in the Indian Ocean. Indian Ocean biogeochemical processes and ecological variability. American Geophysical Union, Washington DC, p 350

McPhaden MJ (2002) Mixed layer temperature balance on intraseasonal timescales in the equatorial Pacific Ocean. J Clim $15: 2632-2647$

Murtugudde R, Beauchamp J, McClain CR (2002) Effects of penetrative radiation on the upper tropical ocean circulation. J Clim 15:470-486

Oliver ECJ, Thompson KR (2010) Madden-Julian Oscillation and sea level: local and remote forcing. J Geophys Res 115:C01003. doi: 10.1029/2009JC005337

Parampil SR, Gera A, Ravichandran M, Sengupta D (2010) Intraseasonal response of mixed layer temperature and salinity in the Bay of Bengal to heat and freshwater flux. J Geophys Res 115:C05002

Resplandy L, Vialard J, Lévy M (2009) Seasonal and intraseasonal biogeochemical variability in the thermocline ridge of the southern tropical Indian Ocean. J Geophys Res 114:C07024. doi: 10.1029/2008JC005246

Reynolds RW, Smith TM, Liu C (2007) Daily high-resolutionblended analyses for sea surface temperature. J Clim 20:54735496. doi:10.1175/2007JCLI1824.1

Roundy PE, Kiladis GN (2006) Observed relationships between oceanic Kelvin waves and atmospheric forcing. J Clim 19:5253-5272

Sakamoto CM, Karl DM, Jannasch HW (2004) Influence of Rossby waves on nutrient dynamics and the plankton community structure in the North Pacific subtropical gyre. J Geophys Res 109:C05032 
Sengupta D, Goswami BN, Senan R (2001a) Coherent intraseasonal oscillations of ocean and atmosphere during the Asian Summer Monsoon. Geophys Res Lett 28:4127-4130

Sengupta D, Senan R, Goswami BN (2001b) Origin of intraseasonal variability of circulation in the tropical central Indian Ocean. Geophys Res Lett 28:1267-1270

Siegel DA, Ohlmann JC, Washburn L (1995) Solar radiation, phytoplankton pigments and the radiant heating of the equatorial Pacific warm pool. J Geophys Res 100:4885-4891

Sweeney C, Gnanadesikan A, Griffies SM (2005) Impacts of shortwave penetration depth on large-scale ocean circulation and heat transport. J Phys Oceanogr 35:1103-1119

Trenberth KE, Large WG, Olson JG (1989) The effective drag coefficient for evaluating wind stress over the oceans. J Clim 2:1507-1516

Uz BM, Yoder JA, Osychny V (2001) Pumping of nutrients to ocean surface waters by the action of propagating planetary waves. Nature 409:597-600. doi:10.1038/35054527

Vialard J, Shenoi SSC, McCreary JP, Shankar D, Durand F, Fernando V, Shetye SR (2009) Intraseasonal response of the northern Indian Ocean coastal waveguide to the Madden-Julian Oscillation. Geophys Res Lett 36:L14606. doi:10.1029/2009GL038450

Vialard J, Jayakumar A, Gnanaseelan C (2011) Processes of 30-90 days sea surface temperature variability in the northern Indian Ocean during boreal summer. Clim Dyn doi. doi: 10.1007/s00382-011-1015-3

Waliser DE (2006) Intraseasonal variability. In: Wang B (ed) The Asian monsoon. Springer, Heidelberg, pp 203-258

Waliser DE, Murtugudde R, Lucas LE (2004) Indo-Pacific Ocean response to atmospheric intraseasonal variability: 2 . Boreal summer and the intraseasonal oscillation. J Geophys Res 109:C03030

Waliser DE, Murtugudde R, Strutton P, Li J-L (2005) Subseasonal organization of ocean chlorophyll: prospects for prediction based on the Madden-Julian Oscillation. Geophys Res Lett. doi: 10.1029/2005GL024300

Waliser DE et al (2009) MJO simulation diagnostics. J Clim 22:3006-3030. doi:10.1175/2008JCLI2731.1

Webber BGM, Matthews AJ, Heywood KJ (2010) A dynamical ocean feedback mechanism for the Madden-Julian Oscillation. Q J R Meteorol Soc 136:740-754

Wetzel P, Maier-Reimer E, Botzet M (2006) Effects of ocean biology on the penetrative radiation in a coupled climate model. J Clim 19:3973-3987

Wheeler MC, Hendon HH (2004) An all-season real-time multivariate MJO index: development of an index for monitoring and prediction. Mon Weather Rev 132:1917-1932

Woolnough SJ, Slingo JM, Hoskins BJ (2000) The relationship between convection and sea surface temperature on intraseasonal timescales. J Clim 13:2086-2104

Wu J (1982) Wind-stress coefficients over sea surface from Breeze to Hurricane. J Geophys Res 87:9704-9706

Wyrtki K (1981) An estimate of equatorial upwelling in the Pacific. J Phys Oceanogr 11:1205-1214. doi:10.1175/1520-0485(1981) 011<1205:AEOEUI $>2.0$. CO;2

Zhang C (2005) Madden-Julian Oscillation. Rev Geophys. doi: 10.1029/2004RG000158

Zhang C, Anderson SP (2003) Sensitivity of intraseasonal perturbations in SST to the structure of the MJO. J Atmos Sci 60:2196-2207

Zhang C, McPhaden MJ (2000) Intraseasonal surface cooling in the equatorial western Pacific. J Clim 13:2261-2276

Zhou L, Murtugudde R (2010) Influences of Madden-Julian Oscillations on the eastern Indian Ocean and the maritime continent. Dyn Atmos Ocean 50:257-274. doi:10.1016/j.dynatmoce.2009.12.003 